\title{
Otimização termoenergética de uma edificação escolar: discussão sobre o desempenho de quatro algoritmos evolutivos multiobjetivo
}

\author{
Thermoenergetic optimization of a school building: \\ discussion of the performance of four multiobjective \\ evolutionary algorithms
}

\author{
Thalita dos Santos Maciel \\ Rodrigo Karini Leitzke \\ Carolina de Mesquita Duarte \\ Fábio Kellermann Schramm \\ Eduardo Grala da Cunha
}

\section{Resumo}

${ }^{1}$ Thalita dos Santos Maciel 1 Universidade Federal de Pelotas Pelotas - RS - Brasil

${ }^{2}$ Rodrigo Karini Leitzke 2Universidade Federal de Pelotas Pelotas - RS - Brasil

${ }^{3}$ Carolina de Mesquita Duarte 3Universidade Federal de Pelotas Pelotas - RS - Brasil

${ }^{4}$ Fábio Kellermann Schramm ${ }^{4}$ Universidade Federal de Pelotas Pelotas - RS - Brasil

${ }^{5}$ Eduardo Grala da Cunha ${ }^{5}$ Universidade Federal de Pelotas Pelotas - RS - Brasil

Recebido em 11/11/20 Aceito em 19/01/21

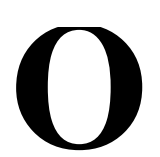

baixo desempenho termoenergético das edificações resultou em uma progressão no consumo final de energia elétrica pelos setores da construção civil. A demanda por climatização artificial contribui significativamente para esse crescimento e pode estar diretamente relacionada a um inadequado planejamento arquitetônico. Através de uma estratégia de otimização multiobjetivo é possível identificar parâmetros de melhoria do desempenho desses edifícios mediante dois ou mais objetivos. Este estudo discute o desempenho de quatro algoritmos de otimização multiobjetivo aplicados a um projeto-padrão Proinfầncia tipo 2 , implantado na zona bioclimática 2. Foram definidas como funções-objetivo a intensidade do uso de energia elétrica (IUE) para aquecimento e resfriamento e foram alteradas cinco variáveis: a espessura do isolamento térmico das paredes externas e do piso, a absortância solar das paredes externas e da cobertura, e a orientação solar. O algoritmo SPEA2 apresentou o melhor desempenho, alcançando uma solução capaz de reduzir aproximadamente $92 \%$ de IUE por aquecimento e $52 \%$ por resfriamento, em relação ao consumo do caso base.

Palavras-chave: Simulação computacional. Otimização baseada em simulação. Otimização multiobjetivo. Eficiência energética.

\section{Abstract}

The low thermoenergetic performance of buildings leads to increasing final consumption of electricity in the construction sector. The demand for air conditioning has contributed significantly to this increase and may be directly related to inadequate architectural planning. Through the establishment of a multi-objective optimization strategy, it is possible to identify performance improvement parameters for these buildings. This study discusses the performance of four multi-objective optimization algorithms applied to a standard project on early childhood education, developed by the Brazilian government program Proinfância, implemented in bioclimatic zone 2. Energy use intensity (IUE) for heating and cooling were defined as objective functions and five variables were changed: the thickness of the thermal insulation of the external walls and the floor, the absorptance of the external walls and roof, and solar orientation. The SPEA2 algorithm showed the best permance, achieving a solution capable of reducing IUE by approximately $92 \%$ in heating and 52\% in cooling, when compared to the reference case.

Keywords: Computer simulation. Simulation-based optimization. Multi-objective optimization. Energy efficiency.

MACIEL, T. dos S.; LEITZKE, R. K.; DUARTE, C. de M.; SCHRAMM, F. K.; CUNHA, E. G. da. Otimização 


\section{Introdução}

Segundo o Balanço Energético Nacional de 2019, as edificações consomem mais de 50\% da energia elétrica produzida no Brasil. Nesse mesmo ano, o país registrou um aumento de 1,3\% no consumo final de eletricidade, sendo que os setores residencial, comercial e público foram os que mais contribuíram para esse aumento (EMPRESA..., 2020). Considerando que grande parte da energia que é consumida pelos edifícios é utilizada durante a fase de uso (CABEZA et al., 2014), o baixo desempenho das edificações e a busca pela garantia de conforto dos usuários tornam a demanda por climatização artificial a principal responsável por grande parcela desse consumo total, contribuindo para o referido crescimento.

No Brasil, é comum que sejam produzidas edificações padronizadas com objetivo de redução de custos e tempo de execução. Kowaltowski (2011) afirma que as instituições públicas frequentemente adotam esses projetos pela mesma premissa. No entanto, se por um lado a adoção de projetos padronizados busca otimizar custos e tempo na concepção do projeto e em sua construção, por outro lado desconsidera questões importantes como a diversidade climática do país. Isso contribui com problemas decorrentes pela falta de conhecimento das demandas específicas de cada local de implantação.

Nesse mesmo cenário, no ano de 2007 o Governo Federal instituiu o Programa Nacional de Reestruturação e Aquisição de Equipamentos para a Rede Escolar Pública de Educação Infantil - Proinfância (BRASIL, 2007), para prestar assistência técnica e financeira aos municípios brasileiros para a construção de novas Escolas Municipais de Educação Infantil (EMEIs) para a melhoria da qualidade da educação infantil da rede pública. Logo, determinou que o Fundo Nacional de Desenvolvimento da Educação (FNDE) fosse o órgão responsável pela concepção dos projetos-padrão para todas as EMEIs a serem construídas com recursos do Proinfância. Em seguida, o FNDE anunciou que a concepção dos projetos-padrão seria baseada em uma revisão das inconsistências dos projetos e manuais técnicos quanto a segurança, habitabilidade e sustentabilidade. No entanto, em um país com grande extensão territorial e oito zonas bioclimáticas com características completamente distintas, conforme divisão estabelecida pela NBR 15220-3 (ABNT, 2005b), um projeto-padrão não se configura como a solução mais adequada para o problema. É inevitável que o baixo desempenho da edificação comprometa o conforto ambiental dos usuários, e ainda acarrete o aumento do consumo de energia pela necessidade de climatização artificial.

Em uma perspectiva projetual, todas as decisões podem exercer grande influência no desempenho térmico e energético de uma edificação. A incorporação de requisitos de desempenho durante a concepção consiste em uma das práticas mais eficientes e econômicas para elaboração de projetos com menor impacto ambiental. Além de traduzir uma posição entre o meio ambiente natural e construído, o ato de projetar envolve inúmeras variáveis que normalmente são inter-relacionadas e caracterizam o sistema complexo e único que é o edifício (NIMLYAT; DASSAH; ALLU, 2014).

Nesse sentido, considerando a complexidade de avaliação de todos os parâmetros que compõem uma edificação, a análise por meio de simulação computacional é frequentemente utilizada na identificação de estratégias para melhoria do desempenho dos edifícios (COAKLEY; RAFTERY; KEANE, 2014). Com a inserção do uso do computador é possível que sejam desenvolvidos modelos que representem sistemas reais de forma gráfica e em um ambiente computadorizado, simulando o comportamento de edificações reais (ZALUSKI; DANTAS, 2018), sejam na fase de projeto ou após sua construção (DIDONÉ; PEREIRA, 2010). Esse tipo de procedimento pode tornar o processo mais investigativo e cauteloso em resposta à crescente preocupação pela diminuição da demanda energética nos edifícios.

Para análises mais precisas é importante que a escolha do software de simulação seja feita cuidadosamente, já que a fidelidade do modelo com o caso real depende diretamente dessa decisão. Segundo Sousa (2012), o software EnergyPlus (EP) é a ferramenta mais reconhecida e utilizada como instrumento para análise computacional de eficiência energética. Ainda que o EP apresente uma grande diversidade de análises, o aperfeiçoamento dessa área tem aliado procedimentos convencionais ao uso de ferramentas baseadas nos princípios da inteligência artificial (IA), possibilitando o aumento da complexidade dos cenários simulados e a relevância dos resultados.

Desse modo, apesar da simulação computacional convencional representar um grande avanço para esse tipo de análise, o processo de otimização no desempenho de uma edificação pode ser um processo demorado. Em seu estudo, Pan et al. (2016) afirmam que esse tipo de procedimento, se feito de forma manual, pode consumir muito tempo, demandar inúmeros testes e muitas vezes ainda tornar-se impraticável para projetos complexos. 
De acordo com Nguyen, Reiter e Rigo (2014), o termo otimização surge como denominação para um processo contínuo de busca que visa encontrar a melhor solução para um determinado problema. Assim, quando métodos de otimização são associados a programas de simulação, passam a ser conhecidos como otimização baseada em simulação (OBS). Esse processo indica maiores chances para obtenção de melhores resultados, já que nesse caso busca-se uma estratégia que passe a atender mais adequadamente um ou mais objetivos específicos já determinados, evidenciando o caminho para alcançar projetos de edificações com melhor desempenho (FONSECA et al., 2017).

Nesse contexto, o objetivo deste trabalho é comparar o desempenho de quatro algoritmos de otimização multiobjetivo. Dois desses algoritmos foram implementados recentemente e contam com um propósito de rápida convergência de resultados, e os outros dois amplamente difundidos na área e considerados algoritmos referência para esse tipo de análise, o NSGA-II (DEB et al., 2002) e o SPEA2 (ZITZLER et al., 2001). Levando em consideração que para construção de novas EMEIs com projetos-padrão é necessário que se faça uma série de ajustes indispensáveis para a melhoria do seu desempenho, a avaliação desses algoritmos será realizada através de um projeto-padrão desenvolvido pelo Proinfância.

\section{Otimização multiobjetivo}

\section{Processo de otimização}

$\mathrm{Na}$ grande área da otimização, alguns problemas necessitam que vários objetivos sejam alcançados e não apenas um. No caso das edificações, geralmente esses objetivos são conflitantes entre si e dificilmente é possível que se encontre uma solução ótima para todos os objetivos de modo simultâneo. Essas características fazem parte de um problema de otimização multiobjetivo (POM), que também pode ser chamado de otimização multicritério ou multiatributo (SAMPAIO, 2011). Para Nguyen, Reiter e Rigo (2014) o processo de otimização pode ser subdividido em três fases: pré-processamento, que consiste na formulação do problema, processo de execução da otimização e pós-processamento, referente à interpretação dos resultados obtidos através da otimização.

Para análise de edificações, o processo de busca geralmente é automatizado com a combinação de um software de simulação e um motor de otimização, que pode consistir na utilização de uma ou mais estratégias de otimização (ATTIA, 2012). Atualmente, a estratégia mais utilizada pela otimização baseada em simulação (OBS) trata justamente disso e estabelece um ciclo entre o algoritmo de otimização e o software simulador vinculado a esse algoritmo, assim como é apresentado na Figura 1. O objetivo desse procedimento é avaliar os indivíduos, já definidos inicialmente, ao longo das futuras gerações.

\section{Figura 1 - Processo de otimização baseada em simulação}

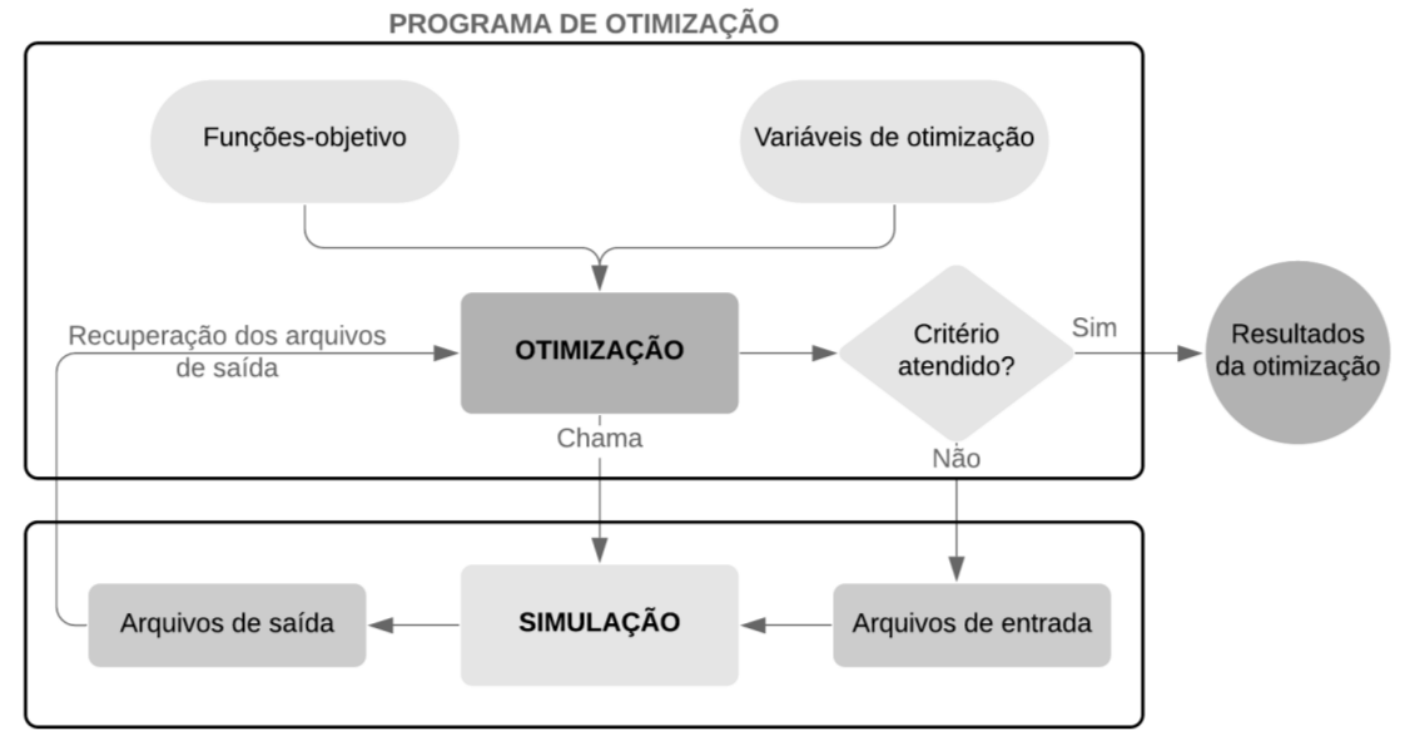

PROGRAMA DE SIMULAÇÃO DE EDIFÍCIOS

Fonte: adaptado de Nguyen, Reiter e Rigo (2014). 
A etapa de escolha do método de otimização é muito importante. Para realização de uma otimização efetiva, é primordial que a definição do algoritmo seja adequada para cada tipo de problema. Isso auxilia na eficiência e robustez da análise, fazendo com que um mesmo problema seja resolvido com menor esforço e sejam identificadas mais soluções (ZEMERO, 2019).

Os algoritmos evolutivos (AE) são utilizados na grande maioria desses estudos (EVINS, 2013). Esses algoritmos surgem como uma vertente da programação evolutiva (FOGEL, 1962), baseiam-se nos mecanismos da evolução biológica, e uma de suas principais características é a utilização de múltiplas funções-objetivo.

Para melhor representação dessas análises, surgiram os algoritmos evolutivos multiobjetivo, que buscam maximizar ou minimizar duas ou mais funções-objetivo conflitantes de um determinado problema (COELLO et al., 2007). Entre estes, os mais utilizados são os evolutivos MOGAs (Multi Objective Genetic Algorithm), e no que diz respeito ao desempenho de edificações, destacam-se o Nondominated Sorting Genetic Algorithm II (NSGA-II) (DEB et al., 2002) e o Strength Pareto Evolutionary Algorithm 2 (SPEA2) (ZITZLER et al., 2001). Esses algoritmos utilizam a curva de Pareto Front, ou Fronteira de Pareto, para estabelecer a região com os melhores resultados, tanto na maximização quanto na minimização das funçõesobjetivo.

\section{Fronteira de Pareto}

Geralmente um problema multiobjetivo é resolvido por meio da construção de um diagrama de Pareto (PARETO, 1896), no qual cada ponto representa uma solução do espaço de soluções viáveis para o problema em questão. A Figura 2 exemplifica esse comportamento e apresenta a curva de Pareto em uma análise multiobjetivo, em que $\mathrm{fl}(\mathrm{x})$ e $\mathrm{f} 2(\mathrm{x})$ representam as duas funções-objetivo, a curva em cinza representa a Fronteira de Pareto formada a partir dos pontos ótimos e os pontos quadriculados representam as soluções não dominadas, sendo estas as que não apresentaram resultados próximos da curva ótima naquela iteração da análise. Em um cenário de minimização, a solução ideal de ambas as funções-objetivo seria aquela que estivesse o mais próximo possível da origem do gráfico $(0,0)$.

\section{Estratégias de otimização do desempenho de edificações}

Diante do crescimento dessas análises, estudos mais recentes passaram a utilizar abordagens de OBS com estratégias mais aprofundadas, do tipo paramétricas (ZHANG; KOROLIJA, 2010), evolutivas (DAHLAN; ARIS, 2018) ou multiobjetivo (YU et al., 2015). Segundo Li e Malkawi (2016) muitas estratégias têm sido utilizadas na redução do consumo de energia de projetos da construção civil, entre elas a modernização de edifícios (ASADI et al., 2012; LEE et al., 2015), o resfriamento de ambientes (HU; KARAVA, 2014; YAN et al., 2016) e o estudo da inserção de parâmetros sustentáveis para melhoramento da qualidade do ar em edificações (TONG et al., 2016a, 2016b). Essas técnicas utilizam princípios de inteligência artificial, na medida em que empregam abordagens inteligentes e tecnológicas, no sentido computacional, para redução do tempo de análise em comparação com os métodos convencionais.

Figura 2 - Comportamento da Fronteira de Pareto em análises multiobjetivo

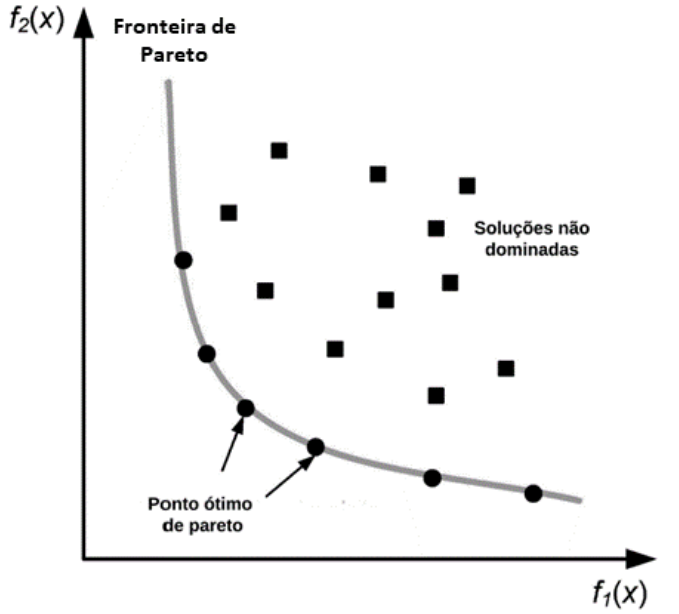

Fonte: adaptado de Huang et al. (2015).

224 Maciel, T. dos S.; Leitzke, R. K.; Duarte, C. de M.; Schramm, F. K.; Cunha, E. G. da 
Esses estudos têm possibilitado o desenvolvimento de inúmeros métodos de OBS em função dos avanços observados na integração entre as áreas da computação e construção. Esses métodos tornaram-se uma alternativa eficaz no aprimoramento do desempenho das edificações, e atualmente essas abordagens têm se concentrado no emprego integrado de uma ferramenta de otimização e de um software de simulação termoenergética, sendo que o EnergyPlus e o TRNSYS, juntamente com a ferramenta Matlab, são os softwares mais comumente utilizados para esse fim (YIGIT; OZORHON, 2018).

$\mathrm{Na}$ área da arquitetura, estudos que utilizam algoritmos de otimização são recentes e avaliam diferentes edificações em inúmeros contextos de implantação. Nos últimos anos, observou-se um crescimento no número de trabalhos que estudam técnicas de otimização de fatores práticos para configuração de envelopes térmicos (ECHENAGUCIA et al., 2015; WU; NG; SKITMORE, 2016; BLUM et al., 2019), buscando compreender a influência que esses fatores exercem no desempenho das edificações, seja este desempenho térmico, energético, lumínico ou visual.

Nesse mesmo sentido, Bre e Fachinotti (2017) desenvolveram um código computacional para otimização multiobjetivo do desempenho de uma edificação residencial multifamiliar, visando à redução do consumo de energia para aquecimento e resfriamento, a partir da alteração de parâmetros, como a orientação solar, composição das paredes externas, piso e cobertura, tamanho e tipo de esquadrias e dispositivos de sombreamento. Em outro estudo, Gan et al. (2019) apresentam uma abordagem de otimização com a utilização de algoritmos genéticos (AG). Considerando que grande parte dos estudos dessa área utilizam edificações térreas, de forma regular e com variáveis de projeto limitadas, essa proposta buscou identificar o projeto ideal para um prédio residencial com 40 andares. Recentemente, Linczuk e Bastos (2020) utilizaram o algoritmo NSGA-II para investigação do potencial de uma otimização multiobjetivo na escolha de soluções projetuais que possibilitassem melhores condições de conforto térmico e redução do consumo de energia elétrica para edificações residenciais localizadas na Região Sul do Brasil.

A otimização de dispositivos de sombreamento também é observada na literatura. Como elementos projetados para impedir a passagem excessiva de luz solar direta e indireta, os dispositivos de sombreamento fazem parte do envelope dos edifícios como componentes integrados e são capazes de reduzir o custo operacional dos sistemas de aquecimento e resfriamento sem bloquear completamente a luz do dia. Nesse contexto, Khoroshiltseva, Slanzi e Poli (2016) abordaram o problema de projetar novos dispositivos estáticos para janelas externas de um edifício residencial em Madri. Para identificação de um conjunto de dispositivos de sombreamento, as soluções foram analisadas pela Fronteira de Pareto. Para esse procedimento, foi utilizada uma ferramenta denominada m-EDO, a qual foi acoplada ao EnergyPlus (EP).

De modo semelhante, Kirimtat et al. (2019) integraram a modelagem paramétrica e a otimização baseada em avaliação de desempenho, e propuseram novas alternativas de projeto para esse tipo de dispositivo com a utilização de painéis amorfos. A análise foi baseada em funções-objetivo de iluminação útil da luz do dia (UDI) e consumo total de energia, e a otimização foi realizada através dos algoritmos NSGA-II e JcGA-DE (Self-adaptive Continuous Genetic Algorithm With Differential Evolution).

A otimização de esquadrias também é um procedimento promissor para o melhoramento dos edifícios. Esses elementos envolvem parâmetros importantes frente ao desempenho térmico, energético e visual dos edifícios. A orientação, o tamanho e o material do vidro e dos caixilhos são variáveis que podem influenciar diretamente nos resultados de desempenho de uma edificação. Dussault e Gosselin (2017) realizaram uma análise de sensibilidade de parâmetros de projetos relacionados com indicadores térmicos e de consumo de energia, em edifícios com vidros eletrocrômicos e smart windows (SW), ou janelas inteligentes, que oferecem flexibilidade de controle quanto a ganhos solares. O modelo foi simulado no TRNSYS (estratégias de controle) e no Radiance/Daysim (simulações de luz do dia e artificial) e posteriormente a etapa de pósprocessamento dos resultados foi implementada no MATLAB.

Zhai et al. (2019) utilizaram um método de otimização multiobjetivo combinando o NSGA-II com o software EP, para otimização dos parâmetros de orientação e tipo de vidro das janelas existentes em uma sala de escritório. A análise foi baseada na Fronteira de Pareto e teve como diferencial a utilização de três funções-objetivo: consumo de energia, desempenho térmico e desempenho visual.

\section{Método de pesquisa}

Este trabalho foi desenvolvido em seis etapas: definição do objeto de estudo, configuração das características da solução base, definição das variáveis de otimização, definição das abordagens de otimização, delimitação das estratégias de implementação e análise de resultados (Figura 3). 
Figura 3 - Delineamento da pesquisa

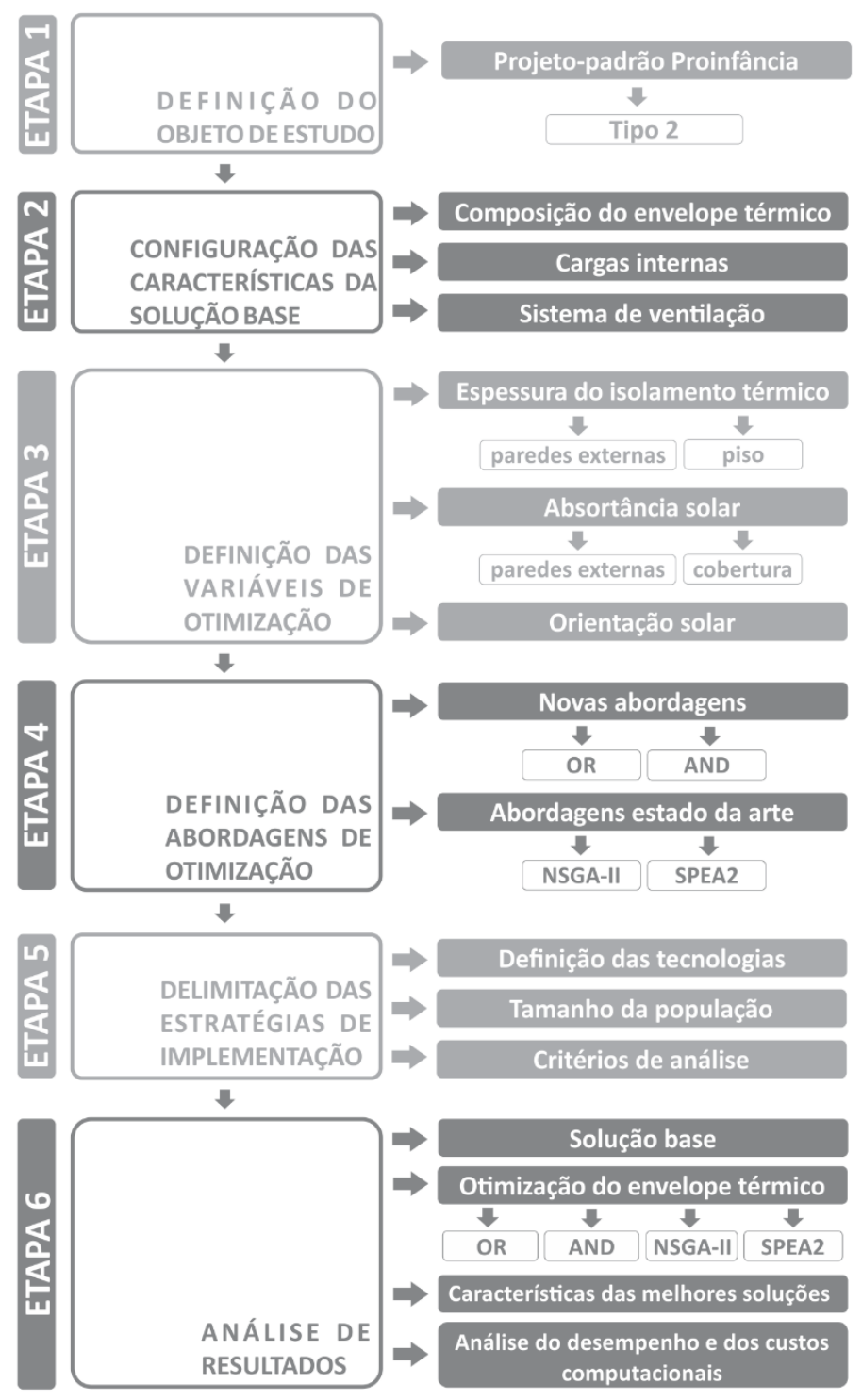

\section{Definição do objeto de estudo}

Para avaliação do comportamento dos algoritmos, foi utilizado como objeto de estudo um projeto-padrão de educação infantil tipo 2, desenvolvido pelo Programa Proinfância. Esse projeto foi escolhido devido à deliberação do Fundo Nacional de Desenvolvimento da Educação (FNDE), que estipulou que os recursos para implantação de novas Escolas Municipais de Educação Infantil (EMEIs) na cidade de Pelotas, RS, zona bioclimática 2, fossem destinados para construção de projetos-padrão com essa tipologia.

Com 890,33 m de área construída, a escola possui capacidade de acolhimento de até 94 crianças em turno integral ou 188 em turnos alternados. Apresenta características de implantação com pavimento único, blocos interligados por um pátio coberto central e áreas externas com playground, jardins e castelo d'água. Com uma setorização visível os ambientes são distribuídos entre os setores pedagógico, administrativo, serviço, pátio coberto e áreas de uso transitório, como mostra a Figura 4.

\section{Caracterização da solução base}

Conforme especificações do Proinfância (BRASIL, 2017), a edificação apresenta um sistema construtivo convencional, com estrutura em concreto armado e fechamentos verticais em tijolos cerâmicos furados, com dimensões de $9 \mathrm{~cm}$ x $19 \mathrm{~cm}$ x $39 \mathrm{~cm}$, para as paredes internas, e $14 \mathrm{~cm}$ x $19 \mathrm{~cm}$ x $39 \mathrm{~cm}$, para as externas. 
As Tabelas 1, 2, 3 e 4 apresentam as principais propriedades da envoltória, calculadas de acordo com o método apresentado na NBR 15220-2 (ABNT, 2005a).

Com relação às cores, o projeto do FNDE prevê a sua utilização de modo a privilegiar as atividades lúdicas relacionadas com a faixa etária dos usuários, porém, devido à ampla gama proposta no memorial descritivo, adotou-se uma padronização na qual as paredes internas e externas possuem pintura em cor única e absortância igual a 0,2 .

As esquadrias são de alumínio natural, com exceção das portas internas, que são em madeira compensada. Os vidros das janelas são temperados, com espessura de $6 \mathrm{~mm}$.

Figura 4 - Setorização da EMEI tipo 2

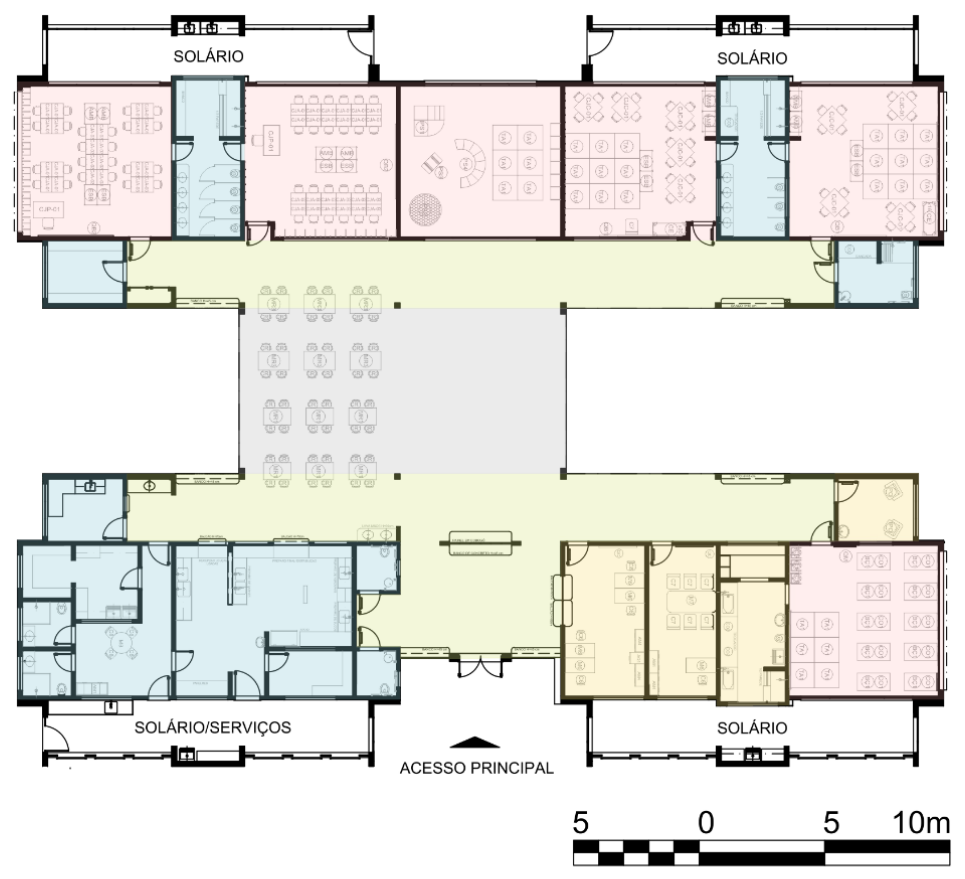

Pedagógico $\square$ Administrativo $\square$ Serviço $\square$ Uso transitório $\square$ Pátio Coberto/Refeitório Fonte: adaptado de FNDE (BRASIL, 2017).

Tabela 1 - Composição das paredes externas

Paredes externas (equivalente à parede com tijolos de nove furos de $14 \mathrm{~cm} \times 19 \mathrm{~cm} \times 39 \mathrm{~cm}$, posicionados a cutelo)

\begin{tabular}{|c|c|c|c|c|c|c|c|}
\hline Composição & $\mathbf{e}(\mathbf{m})$ & $\begin{array}{c}\lambda \\
(W / \mathbf{m K})\end{array}$ & $\begin{array}{c}\mathbf{p} \\
(\mathrm{kg} / \mathrm{m} 3)\end{array}$ & $\begin{array}{c}\mathrm{c} \\
(\mathrm{kJ} / \mathrm{kgK})\end{array}$ & $\begin{array}{c}\mathbf{R} \\
\left(\mathbf{m}^{2} / \mathbf{W K}\right)\end{array}$ & $\begin{array}{c}\mathbf{C T} \\
\left(\mathbf{k J} / \mathbf{m}^{2} \mathbf{K}\right) \\
\end{array}$ & $\begin{array}{c}\mathbf{U} \\
{\left[\mathbf{W} /\left(\mathbf{m}^{2} \mathbf{k}\right)\right]}\end{array}$ \\
\hline Reboco externo & 0,03 & 1,15 & 2000 & 1,00 & \multirow{5}{*}{0,5384} & \multirow{5}{*}{189,05} & \multirow{5}{*}{1,86} \\
\hline Cerâmica & 0,0702 & 0,90 & 534,44 & 0,92 & & & \\
\hline Câmara de ar & 0,04 & & & & & & \\
\hline Cerâmica & 0,0702 & 0,90 & 534,44 & 0,92 & & & \\
\hline Reboco interno & 0,03 & 1,15 & 2000 & 1,00 & & & \\
\hline
\end{tabular}
Nota: Legenda:

$\mathrm{e}=$ espessura;

$\lambda=$ condutividade térmica;

$\mathrm{p}=$ densidade de massa aparente;

$\mathrm{C}=$ calor específico;

$\mathrm{R}=$ resistência térmica;

$\mathrm{CT}=$ capacidade térmica; $\mathrm{e}$

$\mathrm{U}=$ Transmitância térmica. 
Tabela 2 - Composição das paredes internas

\begin{tabular}{|c|c|c|c|c|c|c|c|}
\hline \multicolumn{8}{|c|}{$\begin{array}{c}\text { Paredes internas (equivalente à parede com tijolos } \\
\text { de nove furos de } 9 \mathrm{~cm} \times 19 \mathrm{~cm} \times 39 \mathrm{~cm} \text {, posicionados a cutelo) }\end{array}$} \\
\hline Composição & e (m) & $\begin{array}{c}\lambda \\
(W / \mathbf{m K})\end{array}$ & $\underset{(\mathrm{kg} / \mathrm{m} 3)}{\mathbf{p}}$ & $\begin{array}{c}c \\
(\mathrm{~kJ} / \mathrm{kgK})\end{array}$ & $\underset{\left(\mathbf{m}^{2} / \mathbf{W K}\right)}{\mathbf{R}}$ & $\begin{array}{c}\mathbf{C T} \\
\left(\mathbf{k J} / \mathbf{m}^{2} \mathbf{K}\right)\end{array}$ & $\begin{array}{c}\mathbf{U} \\
{\left[\mathbf{W} /\left(\mathbf{m}^{2} \mathbf{k}\right)\right]}\end{array}$ \\
\hline Reboco externo & 0,03 & 1,15 & 2000 & 1,00 & \multirow{5}{*}{0,4363} & \multirow{5}{*}{151,53} & \multirow{5}{*}{2,29} \\
\hline Cerâmica & 0,0243 & 0,90 & 705,37 & 0,92 & & & \\
\hline Câmara de ar & 0,04 & & & & & & \\
\hline Cerâmica & 0,0243 & 0,90 & 705,37 & 0,92 & & & \\
\hline Reboco interno & 0,03 & 1,15 & 2000 & 1,00 & & & \\
\hline
\end{tabular}

Nota: Legenda:

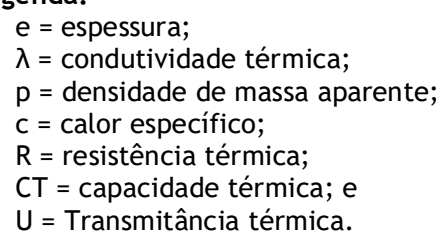

Tabela 3 - Composição do piso

\begin{tabular}{c|c|c|c|c|c|c}
\hline Composição & $\mathbf{e}(\mathbf{m})$ & $\begin{array}{c}\boldsymbol{\lambda} \\
(\mathbf{W} / \mathbf{m K})\end{array}$ & $\begin{array}{c}\mathbf{p} \\
(\mathbf{k g} / \mathbf{m} \mathbf{3})\end{array}$ & $\begin{array}{c}\mathbf{c} \\
(\mathbf{k J} / \mathbf{k g K})\end{array}$ & $\begin{array}{c}\mathbf{R} \\
\left(\mathbf{m}^{2} / \mathbf{W K}\right)\end{array}$ & $\begin{array}{c}\mathbf{U} \\
{\left[\mathbf{W} /\left(\mathbf{m}^{2} \mathbf{k}\right)\right]}\end{array}$ \\
\hline Piso vinílico & 0,004 & 0,02 & 1400 & 1040 & \multirow{2}{*}{0,2171} & 4 \\
\hline Laje em concreto & 0,10 & 1,75 & 2400 & 1000 & \\
\hline
\end{tabular}

Nota: Legenda:

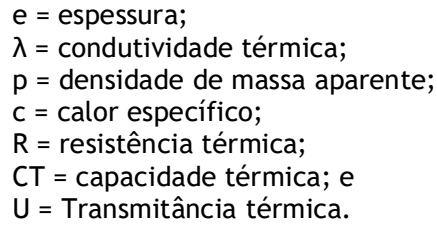

Tabela 4 - Composição da cobertura

\begin{tabular}{|c|c|c|c|c|c|c|c|}
\hline \multicolumn{2}{|c|}{ Composição } & e (m) & $\begin{array}{c}\lambda \\
(W / m K)\end{array}$ & $\begin{array}{c}\mathbf{p} \\
(\mathrm{kg} / \mathrm{m} 3)\end{array}$ & $\begin{array}{c}c \\
(\mathrm{~kJ} / \mathrm{kgK})\end{array}$ & $\begin{array}{c}\mathbf{R} \\
\left(\mathbf{m}^{2} / \mathbf{W K}\right)\end{array}$ & $\begin{array}{c}\mathbf{U} \\
{\left[\mathbf{W} /\left(\mathbf{m}^{2} \mathbf{k}\right)\right]}\end{array}$ \\
\hline \multirow{3}{*}{$\begin{array}{c}\text { Telha } \\
\text { termoacústica } \\
\text { com PIR }\end{array}$} & Telha de aço & 0,0005 & 55 & 7800 & 460 & \multirow{5}{*}{3,1284} & \multirow{5}{*}{0,32} \\
\hline & Isolamento & 0,03 & 0,03 & 40 & 167 & & \\
\hline & Telha de aço & 0,0005 & 55 & 7800 & 460 & & \\
\hline \multicolumn{2}{|c|}{ Câmara de ar } & 0,25 & & & & & \\
\hline \multicolumn{2}{|c|}{ Forro mineral } & 0,015 & 0,038 & 1000 & 840 & & \\
\hline
\end{tabular}

Nota: Legenda:

$\mathrm{e}=$ espessura;

$\lambda=$ condutividade térmica;

$\mathrm{p}=$ densidade de massa aparente;

$\mathrm{C}=$ calor específico;

$\mathrm{R}=$ resistência térmica;

$\mathrm{CT}$ = capacidade térmica; $\mathrm{e}$

$\mathrm{U}=$ Transmitância térmica.

\section{Configuração do modelo numérico}

Para representação do modelo real, a etapa de modelagem foi realizada através do software SketchUp PRO 2019 juntamente com o plugin Legacy Open Studio 1.0.13 (Figura 5). Nesse caso, foram modeladas 26 zonas térmicas e cada uma delas representa um compartimento da edificação. Para configuração do modelo numérico foram utilizadas as especificações de projeto presentes no memorial descritivo fornecido pelo FNDE (BRASIL, 2017). 
Figura 5 - Modelo tridimensional da EMEI tipo 2 utilizando o SketchUP

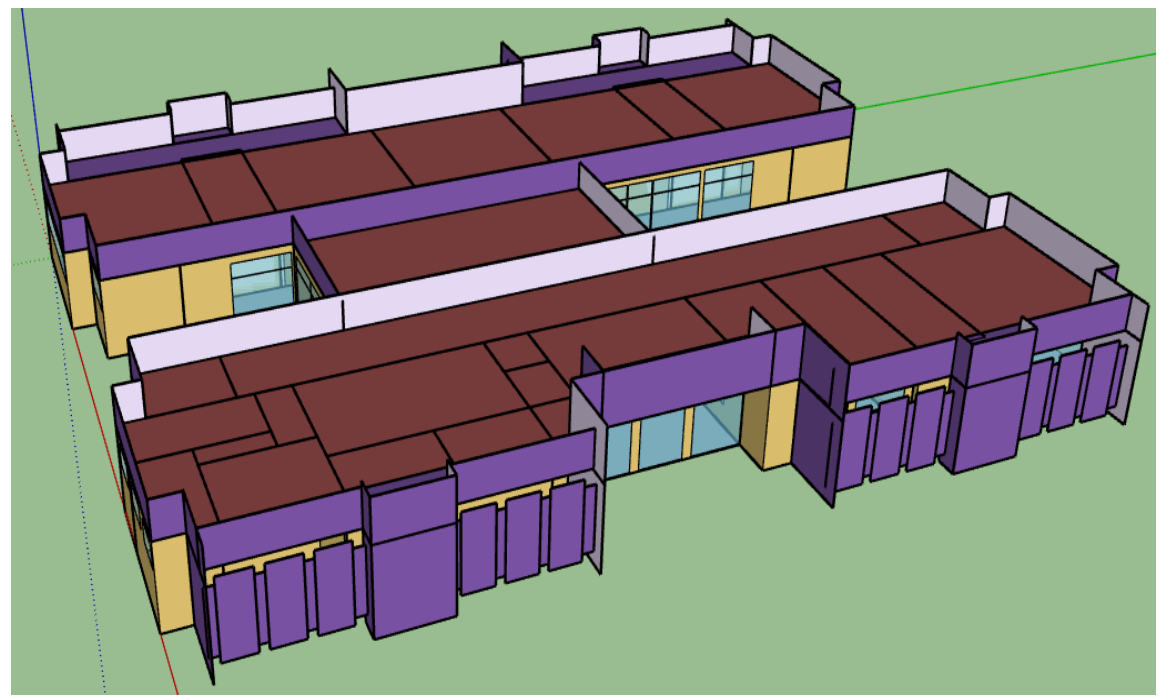

A simulação foi realizada para a zona bioclimática 2 (ZB2), representada pela cidade de Pelotas, RS. Essa zona abrange algumas regiões de estados localizados ao Sul do Brasil e é caracterizada pela grande amplitude de suas temperaturas ao longo do ano. $\mathrm{O}$ arquivo climático utilizado para simulação foi elaborado por Leitzke et al. (2018) e considera o método TRY a partir dos dados climáticos disponibilizados pela Estação Agroclimatológica de Pelotas, conveniada com a Empresa Brasileira de Pesquisa Agropecuária (Embrapa). As temperaturas do solo foram definidas através de um pré-processador do EnergyPlus (EP), denominado Slab.

\section{Configuração das cargas internas}

Para configuração do comportamento de uso e ocupação foram utilizados os dados fornecidos pela $5^{\text {a }}$ Coordenadoria Regional de Educação de Pelotas ( $5^{\mathrm{a}} \mathrm{CRE}$ Pelotas), através da previsão do número de usuários e do horário de realização das atividades na escola. $\mathrm{O}$ número de funcionários é referente à quantidade de crianças atendidas. O horário de funcionamento da EMEI acontece entre 7 h30 e 17h30, de segunda a sexta-feira, com exceção dos feriados.

Para determinação da densidade dos ambientes utilizou-se o método de cálculo de superfície corporal pela Equação de DuBois (DUBOIS; DUBOIS, 1916), levando em consideração o peso e a altura dos usuários por uma média de faixa etária, devido ao compartilhamento dos ambientes entre adultos e crianças.

A configuração dos ganhos internos de iluminação e equipamentos foi realizada com base nos projetos complementares fornecidos pelo FNDE (BRASIL, 2017). O sistema de iluminação foi configurado de acordo com os valores obtidos a partir do projeto elétrico e do cálculo da densidade de potência instalada (DPI) de cada compartimento. Para os equipamentos, o mesmo procedimento foi adotado. O quantitativo de utensílios foi feito com base nas informações disponibilizadas em projeto, e uma estimativa de consumo médio mensal de eletrodomésticos do Programa Nacional de Conservação de Energia Elétrica (PROCEL) foi utilizada para caracterização do tempo de uso e potência dos equipamentos (ELETROBRAS, 2016).

\section{Características do sistema de ventilação}

Uma das alternativas para redução do consumo de energia de uma edificação é a utilização de um sistema misto de ventilação, ou seja, um sistema híbrido. Essa estratégia consiste na utilização da alternância entre ventilação natural com janelas operáveis (manual ou automaticamente controladas) e sistemas mecânicos de condicionamento de ar (CENTER..., 2020), combinando as melhores características de ambos os sistemas (CHARTERED..., 2000). Essa ação, além de facilitar a economia de energia das edificações, também auxilia no aumento da qualidade do ar interno e satisfação dos usuários.

A estratégia de controle adotada para operação desse sistema considera os limites de conforto adaptativo mencionados pela Standard 55 (AMERICAN..., 2013), com 80\% de aceitabilidade. Nessa situação, a climatização artificial só será utilizada quando, durante o período de ocupação da EMEI, os ambientes de permanência prolongada não apresentarem temperaturas dentro desses limites. 
Nesse caso, o sistema de condicionamento foi configurado com um coeficiente de performance (COP) de 2,75 para aquecimento e 3,0 para resfriamento. A taxa de fluxo de ar por pessoa é de $0,0075 \mathrm{~m} / \mathrm{s}$ e a eficiência do motor e do ventilador possuem valores de 0,90 e 0,70 , respectivamente, acordado com o RTQR (INSTITUTO..., 2010), devido à ausência dessas informações no regulamento que corresponde a edificações comerciais/públicas.

\section{Definição das variáveis de otimização e seus respectivos intervalos}

Estudos como os de Oliveira (2012) e Soares (2014) mostram que o aumento do atraso térmico em fechamentos opacos é favorável para elevação dos índices de conforto térmico de uma edificação residencial, assim como para a redução de graus-hora necessários para mantê-la dentro do intervalo de temperatura da zona de conforto térmico. Por esse motivo, a configuração de envelope do caso base foi mantida, assim como sua capacidade térmica, e optou-se pela inserção de um elemento de isolamento térmico pelo lado externo das composições. Essa decisão considera a baixa densidade aparente do material e também a possibilidade de variação de sua espessura como estratégia de otimização. Para as paredes externas utilizou-se a configuração do Capoto, método de isolamento de paredes e proteção dos edifícios pelo exterior, em que são fixadas placas de poliestireno expandido (EPS) nas fachadas. Do mesmo modo, para o piso, a configuração das placas de poliestireno extrudado (XPS) atua como isolamento térmico do fechamento. Na cobertura, com baixa transmitância térmica já observada na solução base (preenchimento em PIR e transmitância térmica de $0,32[\mathrm{~W} /(\mathrm{m} \mathrm{k})])$, o único parâmetro variado foi a absortância solar. Além dessas variáveis, também foram alteradas a absortância solar das paredes externas e a orientação solar da edificação. As variáveis e seus respectivos intervalos são apresentados na Tabela 5.

\section{Delimitação das abordagens de otimização}

Conforme citado anteriormente, muitos trabalhos têm utilizado algoritmos multiobjetivo para análise do desempenho de edificações. A grande maioria desses trabalhos utiliza como critério de avaliação dos indivíduos das suas populações a curva de Pareto Front, ou Fronteira de Pareto, através dos algoritmos NSGA-II (DEB et al., 2002) e SPEA2 (ZITZLER et al., 2001), considerados referência para a área. Nesse contexto, propõe-se para esse estudo um novo método evolutivo multiobjetivo elitista que utiliza a distribuição normal como uma possível inovação para avaliar o comportamento de cada uma das variáveis em cada geração. Os próximos itens tratam do detalhamento dos quatro algoritmos de otimização empregados no objeto de estudo.

\section{OR e AND}

Essas duas novas abordagens foram implementadas com base nos algoritmos NSGA-II e SPEA2, visando ao aprimoramento de estratégias elitistas e redução de custos computacionais para execução. Para as duas abordagens, a estrutura inicial é a mesma. A partir da seleção das variáveis e dos seus respectivos limites, um conjunto amostral de dados com tamanho pré-definido pelo usuário é gerado aleatoriamente. Então, cada indivíduo desse conjunto é composto pelos valores sorteados para cada uma das variáveis com base nos limites estabelecidos inicialmente. Os indivíduos são avaliados de acordo com os valores referentes às funções-objetivo de intensidade do uso de energia elétrica (IUE) para aquecimento ( $\mathrm{kWh} / \mathrm{m}$.ano) e intensidade do uso de energia elétrica (IUE) para resfriamento $(\mathrm{kWh} / \mathrm{m}$.ano). Em seguida, os indivíduos relacionados com os seus resultados das funções-objetivo compõem a população inicial da análise. Para determinação das gerações seguintes a abordagem 1 (OR) ou a abordagem 2 (AND) devem ser selecionadas.

Tabela 5 - Variáveis de otimização

\begin{tabular}{c|c}
\hline \multicolumn{2}{c}{ Variáveis de otimização } \\
\hline Parâmetro & Limites \\
\hline Espessura do isolamento térmico - paredes externas $(\mathrm{m})$ & $0,001-0,10$ \\
Espessura do isolamento térmico - piso $(\mathrm{m})$ & $0,001-0,15$ \\
Absortância solar das paredes & $0,2-0,9$ \\
Absortância solar da cobertura & $0,2-0,9$ \\
Orientação $\left(^{\circ}\right)$ & $0-360$ \\
\hline
\end{tabular}

Nota: ${ }^{1}$ correspondente a uma transmitância de $0,34 \mathrm{~W} / \mathrm{m}^{2} \mathrm{~K} /{ }^{2}$ Correspondente a uma transmitância de $0,25 \mathrm{~W} / \mathrm{m}^{2} \mathrm{~K}$. 
Os dados de ambos os objetivos são obtidos por meio dos relatórios de saída da simulação computacional com o software EP versão 8.7, e a implementação dos algoritmos é baseada na biblioteca Eppy (EnergyPlus Python) (PHILIP; TRAN; TANJUATCO, 2020), desenvolvida para uma linguagem de programação Python, onde são realizadas as simulações com EP.

Para avaliação dos indivíduos aptos, para cada uma das variáveis é atribuída uma distribuição normal composta pelos valores utilizados em cada indivíduo, definindo assim um sigma que será utilizado para definição de novos valores limites para as variáveis durante as próximas gerações. Assim, além da utilização da Fronteira de Pareto, a curva de distribuição normal ou gaussiana também auxiliará no ajuste de valores de todas variáveis que possuem características que não sejam constantes.

Desse modo, para cada uma das variáveis consideradas na avaliação das abordagens, será criada uma distribuição normal baseada nos valores de formação de cada indivíduo. Como representado na Figura 6, os valores das variáveis que estiverem mais próximos do centro da distribuição normal serão aqueles com maior chance de participarem da definição dos novos limites de valores para os indivíduos das próximas gerações.

Diante desse cenário, foram utilizadas para este trabalho duas novas abordagens evolutivas multiobjetivo elitistas, baseadas na utilização da distribuição normal, denominadas abordagem 1 (OR) e abordagem 2 (AND). As propostas de recorte para o afunilamento das condições dessas duas abordagens estão atreladas à justificativa da distribuição normal como recurso estatístico para identificação das condições de maior impacto na configuração das variáveis. Pontos próximos da região central do sino da curva de distribuição indicam uma concentração dos resultados a partir das estratégias de afunilamento, e esse comportamento implica a perpetuação das melhores configurações em função da maior probabilidade destes no sorteio de composição dos indivíduos. Ambas podem ser consideradas abordagens elitistas na ótica das análises evolutivas.

\section{Abordagem 1 (OR)}

$\mathrm{Na}$ abordagem 1, denominada $\mathrm{OR}$, os indivíduos que fizerem parte dos $50 \%$ dos melhores resultados no eixo $\mathrm{X}$ ou no eixo Y do plano cartesiano de representação são selecionados e então passam a fazer parte da próxima geração. Nesse caso, mesmo que um indivíduo apresente funções-objetivo não satisfatórias para fazer parte do grupo de selecionados em algum dos eixos, ainda pode ser considerado um indivíduo apto se apresentar resultados bons no outro eixo, ou seja, nessa abordagem não são descartados potenciais bons resultados por serem pouco representativos em um dos seus objetivos. Se durante a execução um indivíduo apresentar bons valores em apenas um dos eixos, operadores de mutação são utilizados para alteração de algumas das suas características para busca por melhores resultados em suas funções-objetivo.

\section{Abordagem 2 (AND)}

$\mathrm{Na}$ abordagem AND, 50\% dos indivíduos da geração que apresentaram os melhores resultados em ambos os objetivos são selecionados. Uma das principais características dessa abordagem é a busca pelo elitismo. Assim, apenas os melhores indivíduos são selecionados. Essa característica influencia diretamente a convergência das gerações, já que em poucas gerações os indivíduos são capazes de convergir para regiões com bons resultados. Contudo, diferente da abordagem $O R$, essas situações permitem que potenciais bons indivíduos possam ser descartados caso estes não façam parte do grupo ótimo selecionado nas primeiras gerações.

\section{Figura 6 - Porcentagem de seleção dos sigmas na distribuição normal}

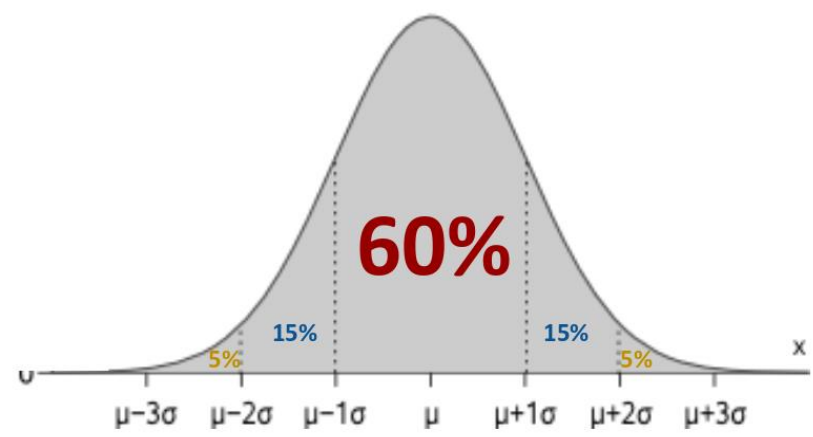




\section{Seleção dos indivíduos aptos e novas gerações}

Para as novas gerações, os resultados são agrupados aos das gerações anteriores, realimentando o conjunto inicial de dados. A justificativa para essa estratégia passa pela contínua utilização da amplitude dos valores que constituem as variáveis e, além disso, ao utilizar os resultados obtidos nas gerações passadas exclui-se a possibilidade de perda dos indivíduos ótimos, já que estes estarão sempre participando do processo evolutivo. Em análises evolutivas com grande explosão combinatória, desconsiderar um determinado indivíduo pode representar a perda dos limites utilizados nas suas variáveis e, sobretudo na abordagem AND, manter uma elite concisa e povoada é fundamental para que exista melhora na convergência dos resultados das funções-objetivo. A Figura 7 apresenta um fluxograma das etapas da estratégia evolutiva apresentada.

\section{NSGA-II e SPEA2}

A busca por estratégias com rápida convergência de dados ampliou a investigação de métodos que priorizasse o desempenho da curva de convergência ótima em uma quantidade menor de gerações. Nessa lógica, atualmente, o NSGA-II e o SPEA2 estão entre as abordagens mais utilizadas para análises evolutivas multiobjetivos.

\section{Abordagem 3 (NSGA-II)}

Entre os algoritmos existentes na literatura e utilizados para problemas de otimização multiobjetivo, o NSGA-II (DEB et al., 2002) é o mais popular. Baseado em uma ordenação elitista por dominância, esse algoritmo utiliza do conceito de dominância para avaliação de cada um dos indivíduos de sua população. Diferente do SPEA2, não precisa armazenar soluções não dominadas, pois é elitista e preserva apenas as melhores soluções de cada população. Nesse contexto, em uma população $P$, com indivíduos $p$ e $q, q$ será dominado por $p$, se $p$ for melhor do que $q$ em, pelo menos, um dos seus objetivos. Esse método permite que os indivíduos mais aptos sejam classificados, bem como a distância de cada um deles até o ponto ótimo. Assim, quanto maior o número de indivíduos dominados por $p$ e menor a sua distância até o ponto ótimo, melhor será a sua classificação.

\section{Abordagem 4 (SPEA2)}

Proposto por Zitzler et al. (2001), o SPEA2 trata de uma abordagem evolutiva que, assim como o NSGA II, utiliza duas populações durante sua execução, sendo uma delas gerada pelas operações evolutivas $(P)$ e a outra denominada população externa $(Q)$, apenas com soluções não dominadas encontradas pelo algoritmo. Denota-se $P y$ e $Q y$ as populações $P$ e $Q$ na geração $y$.

\section{Figura 7 - Fluxograma das abordagens evolutivas AND e $O R$}

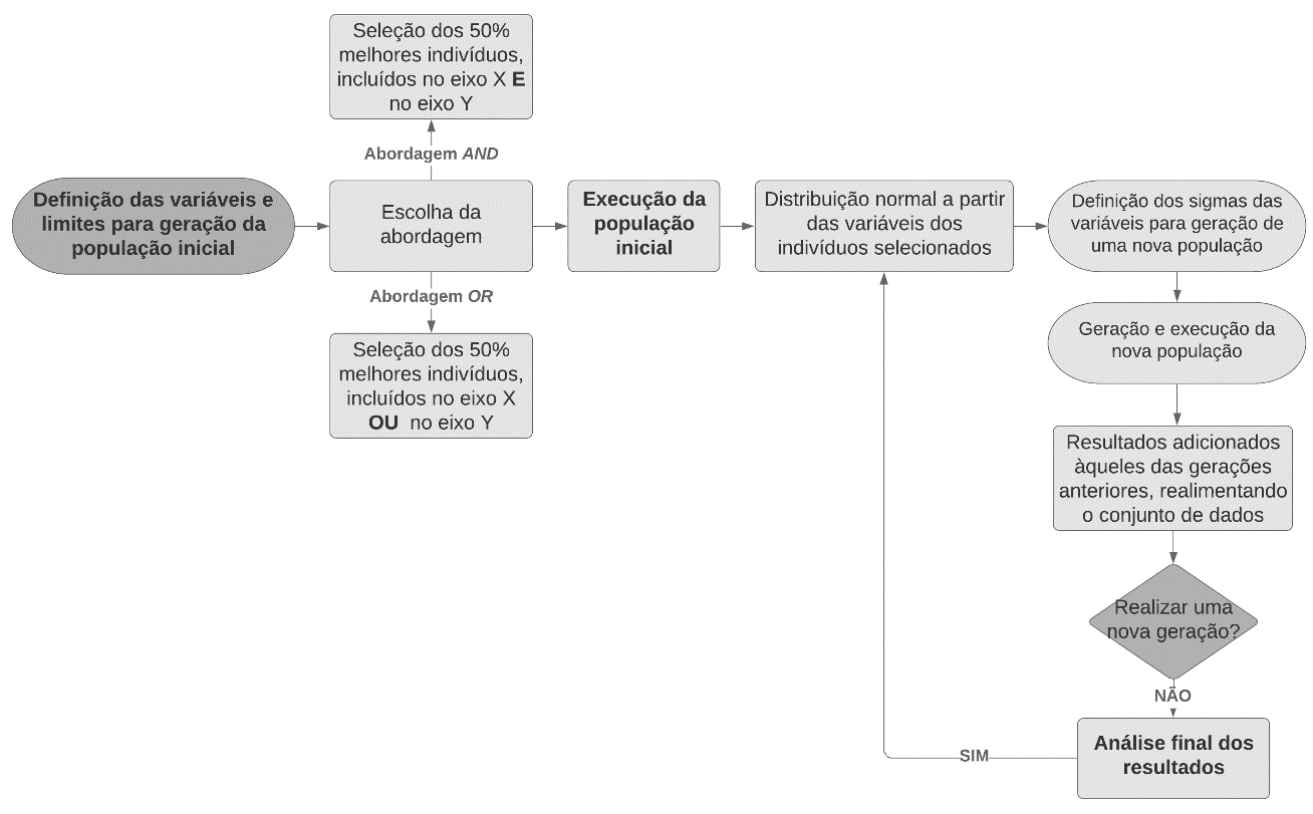

232 Maciel, T. dos S.; Leitzke, R. K.; Duarte, C. de M.; Schramm, F. K.; Cunha, E. G. da 
Para início da análise, suas populações são criadas e então $Q$ é povoada com a população inicial e $P$ é mantida vazia. Posteriormente, todos os indivíduos não dominados pela união de $P y$ e $Q y$ são adicionados em $Q y+1$. Caso o número dessas soluções seja maior que o observado em $P$ ou $Q$, uma redução entre essas soluções é realizada. O objetivo do algoritmo é de fazer com que seja observada uma convergência rápida em $Q$, sem considerar possíveis bons resultados em $P$. Assim, após a execução de algumas gerações, casos interessantes podem ser encontrados a partir da combinação entre os valores de $P$ e bons resultados de $Q$, passando a integrar o novo conjunto da população $Q$. Esse procedimento garante que os dados inicialmente não dominados pelo algoritmo sejam revisados, dificultando o descarte de possíveis indivíduos com bons resultados. Tanto o SPEA2 quanto o NSGA-II utilizam da Fronteira de Pareto para estabelecer a região com os melhores resultados, sejam para maximização ou minimização de suas funções-objetivo.

\section{Delimitação das estratégias de implementação}

\section{Definição das tecnologias}

Como um instrumento que visa facilitar o processo de otimização dos modelos de simulação com o EnergyPlus (EP), foi utilizada a linguagem de programação de computadores Python. Essa linguagem se destaca por ser interpretada (sem a necessidade de compilação), com alto nível de abstração e com uma sintaxe simples de desenvolvimento (MILLMAN; AIVAZIS, 2011).

A escolha do Python se relaciona com o protagonismo da linguagem em relação às demais linguagens de programação de propósito geral. Segundo os dados do $M a d n i g h t^{1}$, que avalia a criação de repositórios de códigos entre as linguagens de programação, o Python aparece em primeiro entre essa categoria, com $15,89 \%$ dos repositórios criados.

A relação entre o Python e o EP, neste trabalho, está pautada na utilização da já referida plataforma BESOS, desenvolvida em 2019 pelo Energy Incities da Victoria University no Canadá (ENERGY INCITIES, 2020). Essa plataforma busca relacionar os recursos implementados em bibliotecas do Python com as simulações térmicas e energéticas do EP. Dos recursos ofertados pela BESOS, a biblioteca Python chamada platypus apresenta a implementação dos algoritmos evolutivos NSGA-II e SPEA2, além da integração com os recursos da biblioteca eppy que comunica o Python com o EnergyPlus. Através da BESOS é possível realizar as otimizações dos modelos de forma local ou remota, sendo a segunda opção realizada em parceria com a instituição autora da aplicação em função do uso de seus servidores. Neste trabalho as execuções foram realizadas em um hardware local em função da disponibilidade desse recurso.

Dessa forma, para a execução das abordagens AND e OR foram utilizados os recursos nativos do Python e do EP para execução dos experimentos, considerando um número menor de gerações $(3,5$ e 7$)$, em função do custo computacional desses algoritmos, elaborados de modo a executar os modelos de simulação com recursos de retroalimentação dos dados de saída, buscando um afunilamento dessas informações no processo de busca pelos melhores resultados das funções-objetivo no sentido da minimização. Para execução do NSGA-II e SPEA2, o Python e o EP foram utilizados por intermédio dos recursos da BESOS, permitindo com que um número maior de gerações fosse testado $(30,50$ e 100), muito em função das diferenças nas implementações desses dois algoritmos da literatura utilizados pelo trabalho, que não consideram a retroalimentação dos dados, apresentando, dessa forma, uma menor complexidade computacional em simulações custosas.

A avaliação dos indivíduos foi realizada com base nos valores das funções-objetivo. Para este estudo, foram definidas como funções-objetivo a minimização da intensidade do uso de energia elétrica (IUE) para resfriamento, eixo $x$ do plano cartesiano de representação, e também a minimização de IUE para resfriamento, referente ao eixo $y$. Os dados de ambos os objetivos foram obtidos por meio dos relatórios de saída da simulação do EP.

\section{Tamanho da população}

As variáveis de otimização apresentadas na Tabela 5 foram utilizadas como critério para a definição do tamanho da população inicial. Esse procedimento foi realizado a partir da Equação 1, que define o tamanho de uma amostra com base no tamanho da população, da margem de erro e do escore z (DANIEL; CROSS, 2018).

1https://madnight.github.io/githut/\#/pull_requests/2020/3. Acesso em: 17 dez. 2020. 
$T=\frac{\frac{z^{2} \times p(1-p)}{e^{2}}}{1+\left(\frac{z^{2} \times p(1-p)}{e^{2} N}\right)}$

Eq. 1

Onde:

$T=$ Tamanho da amostra;

$N=$ Tamanho da população;

$e=$ margem de erro; e

$z=$ escore $z$.

Nesse caso, o tamanho da população $(T)$ corresponde ao produto de todas as possibilidades de combinação das variáveis de otimização, a margem de erro $(e)$ à porcentagem que indica o nível de correspondência dos resultados em comparação a esse produto e o escore z $(z)$ ao número de desvios padrão entre determinada proporção e a média. O tamanho da amostra obtida para a formação das populações foi de 69 indivíduos. Esse valor considera uma margem de erro $(e)$ de $10 \%$ e um escore $\mathrm{z}(z)$ de 1,65 , que corresponde a um nível de confiança de $90 \%$.

\section{Critérios de análise}

O método de Pareto Front, ou Fronteira de Pareto, foi utilizado para determinar o conjunto ótimo das soluções. Esse método baseia-se na premissa da intersecção entre as regiões dominadas (conjunto bruto de indivíduos obtidos através das simulações) e as regiões não dominadas (região ainda não alcançada pelos resultados obtidos pelas simulações). O que se busca, portanto, é identificar a região de fronteira entre o que foi obtido até o momento e a região ainda não alcançada, sendo esse o conjunto ótimo de soluções entre as funções-objetivo (NGATCHOU; ZAREI; EL-SHARKAWI, 2005).

Além disso, considerando a possibilidade de predomínio de uma função-objetivo sobre a outra, foi definido um critério de seleção para caracterização das soluções mais eficientes. Foram selecionadas para análise apenas as soluções que não apresentaram um somatório de consumo superior a $10 \%$ do somatório da melhor solução da abordagem (referente àquela com menor valor de IUE no eixo com maior consumo inicial). Isso significa que, quando uma grande diferença, em termos percentuais, é observada entre a melhor solução e as demais, essas composições foram eliminadas da análise.

Para cada uma das abordagens foi realizada uma análise com base na caracterização das soluções da Fronteira de Pareto, na solução ideal, correspondente àquela que apresentar o menor consumo entre as demais soluções e também no desempenho e nos custos computacionais das análises, executadas através de um computador com processador Intel Core i7-2600K CPU 3.40GHz x 8, com 16GB de memória RAM e sistema operacional Ubuntu 18.04.4 LTS (64bits).

\section{Resultados e discussões}

Nesta etapa, são apresentados os resultados do modelo de solução base, e posteriormente os resultados da otimização com os algoritmos multiobjetivo, para a zona bioclimática 2 .

\section{Solução base}

Anteriormente ao processo de otimização multiobjetivo, o modelo foi avaliado mediante simulação computacional convencional por intermédio do software EnergyPlus. Quando a eficiência energética dessa edificação é analisada, nota-se que o maior consumo é destinado ao seu resfriamento, correspondendo a $22,51 \mathrm{kWh} / \mathrm{m}$.ano. Sabe-se que a alta transmitância térmica do envelope possibilita maiores trocas de calor entre o interior e o exterior da edificação, porém, em um modelo em que o ganho interno é elevado, o tempo necessário para essa troca é maior. Ou seja, o envelope com alta transmitância térmica contribui para o resfriamento da edificação, mas apenas durante a noite, quando já não existe ocupação na escola e a temperatura externa é inferior a interna. Considerando o inverno rigoroso da ZB2 esse fenômeno deve ocorrer também com maior facilidade durante esse período, evidenciando o baixo consumo por aquecimento, de apenas $1,70 \mathrm{kWh} / \mathrm{m}$.ano.

Durante o horário de ocupação, de forma mais evidente no verão, a edificação ganha calor através do envelope (opaco e transparente) por condução e radiação solar direta, o que pode se agravar com a carga interna gerada em seu interior. Nesse período, quando o conforto térmico já não pode ser mantido por meio

234 Maciel, T. dos S.; Leitzke, R. K.; Duarte, C. de M.; Schramm, F. K.; Cunha, E. G. da 
da ventilação natural, a climatização artificial é então ativada, fazendo com que o consumo por resfriamento seja consideravelmente elevado quando comparado ao de aquecimento.

\section{Otimização do envelope térmico com algoritmos evolutivos multiobjetivo}

Nenhuma das abordagens alcançou um único ponto de Pareto, ou seja, não foram identificadas soluções que apresentassem os menores valores de consumo para ambas as funções-objetivo. Por esse motivo, conforme estipulado pelos critérios de análise, a caracterização das melhores soluções levou em consideração o eixo de IUE por resfriamento, devido ao maior impacto que essa função exerce sobre o consumo final da edificação.

\section{Resultados da abordagem 1 (OR)}

A Figura 8a apresenta os resultados encontrados pela abordagem 1, no contexto de 3, 5 e 7 gerações. Com base nesses resultados é possível observar que o algoritmo tem um potencial maior de exploração para as primeiras soluções, aquelas alcançadas entre a população inicial e as primeiras gerações. Ao analisar o gráfico referente a 5 e 7 gerações, pode-se constatar que novas soluções se concentram distantes da Fronteira de Pareto, originando resultados piores que os esperados. Esse cenário demonstra a dificuldade do algoritmo em identificar soluções que satisfaçam ambas as funções-objetivo, já que nessa mesma concentração podem ser observadas soluções que reduziram o consumo por aquecimento e aumentaram o consumo por resfriamento, ocasionando essa concentração distante do ponto ótimo $(0,0)$.

Com relação ao desempenho da abordagem, ambas as funções-objetivo possibilitaram a redução do consumo de energia demandado pelo caso base. No eixo IUE resfriamento os valores ficaram entre 17,42 e 32,55 $\mathrm{kWh} / \mathrm{m}$.ano e IUE aquecimento entre 0,23 e $0,45 \mathrm{kWh} / \mathrm{m}$.ano, evidenciando o que foi mencionado anteriormente, onde foram observadas soluções com um consumo por resfriamento maior que o do modelo inicial.

Assim, levando em consideração o menor valor para o eixo de IUE resfriamento, a Figura 8b apresenta a melhor solução encontrada pela abordagem 1 (S1), identificada após a execução de cinco gerações. Essa composição das variáveis possibilitou uma redução de aproximadamente $23 \%$ para o consumo por resfriamento e $78 \%$ por aquecimento, respectivamente com 17,42 e $0,38 \mathrm{kWh} / \mathrm{m}$.ano.

Figura 8 - Resultados da abordagem 1
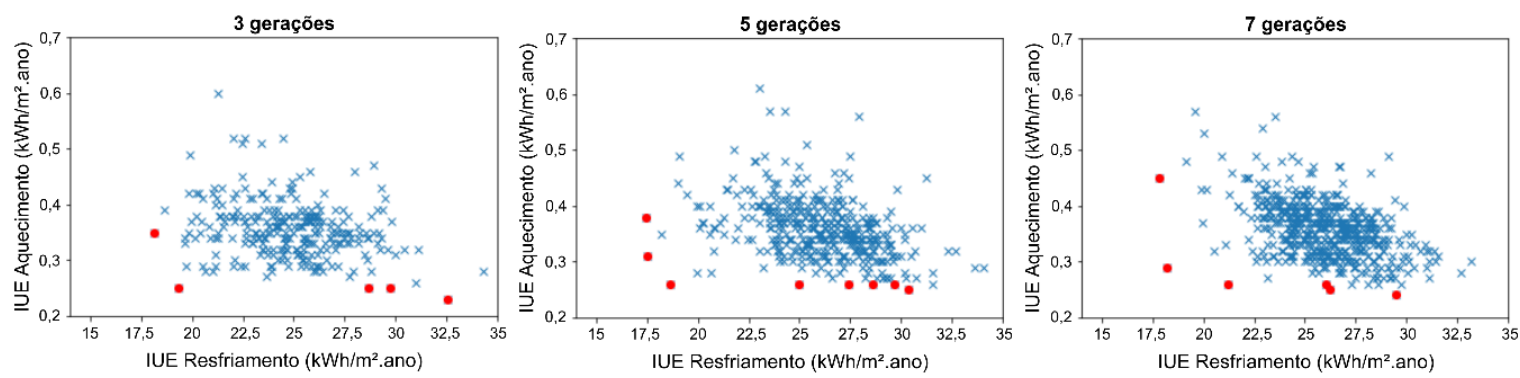

$\times$ Todas as soluçōes - Fronteira de Pareto

(a)

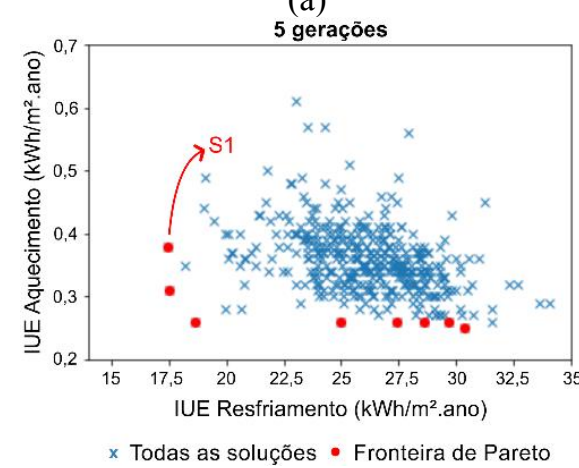

(b) 
Essa redução é ocasionada por uma edificação combinada com suas maiores fachadas (referente aos ambientes de permanência prolongada, com solário) voltadas a orientação leste (L) / oeste (O), e um envelope térmico isolado verticalmente, com 3 centímetros $(\mathrm{cm})$ de isolamento nas paredes, paredes e cobertura em cores claras, com absortâncias de 0,2 e 0,3 , e baixo isolamento no piso, com apenas $1 \mathrm{~cm}$ de XPS.

Para análise da orientação, foram consideradas as maiores fachadas da edificação, referentes àquelas com maior percentual de abertura envidraçada e que abrigam os ambientes considerados de permanência prolongada (salas de atividades). Essas fachadas possuem proteção solar através de solários, e nessa abordagem foram direcionadas para três diferentes orientações, norte (N) / sul (S), leste (L) / oeste (O) e noroeste $(\mathrm{NO})$ / sudeste (SE).

Das 19 soluções da Fronteira de Pareto, apenas 6 foram selecionadas pelo critério definido para análise, sendo a melhor solução uma composição de variáveis com somatório do consumo por climatização artificial de $17,80 \mathrm{kWh} / \mathrm{m}$.ano.

A Figura 9 apresenta as características dessas soluções, e, para cada uma das orientações, podem ser observadas duas composições de variáveis. O nível de isolamento de cada uma das variáveis foi simplificado por limites e organizado por cores, visando ao melhor entendimento da análise. As variáveis representadas na cor cinza possuem características com alto isolamento, as laranjas médio e as amarelas baixo, assim como é apresentado na legenda.

Com as maiores fachadas orientadas $\mathrm{L} / \mathrm{O}$, ambas as soluções apresentam pequena espessura de isolamento no piso como também baixos coeficientes de absortância solar, tanto para paredes quanto para cobertura, o que faz com que esses elementos se mantenham mais isolados. Apesar de todas as outras semelhanças, apenas uma das soluções mantém esse isolamento também na composição do envelope vertical, indicando uma espessura de $7 \mathrm{~cm}$ de EPS.

$\mathrm{Na}$ orientação N/S, o padrão se mantém para as duas soluções. Ambos os casos apresentam um envelope com paredes bem isoladas, espessura de isolamento próximo ao limite superior, e diferentes dos outros casos, com absortâncias em valores médios. Para cobertura são indicadas cores claras, através de uma absortância de 0,2, e para o piso mínimas espessuras de isolamento, de apenas $1 \mathrm{~cm}$.

Figura 9 - Composição das melhores soluções encontradas pela abordagem OR
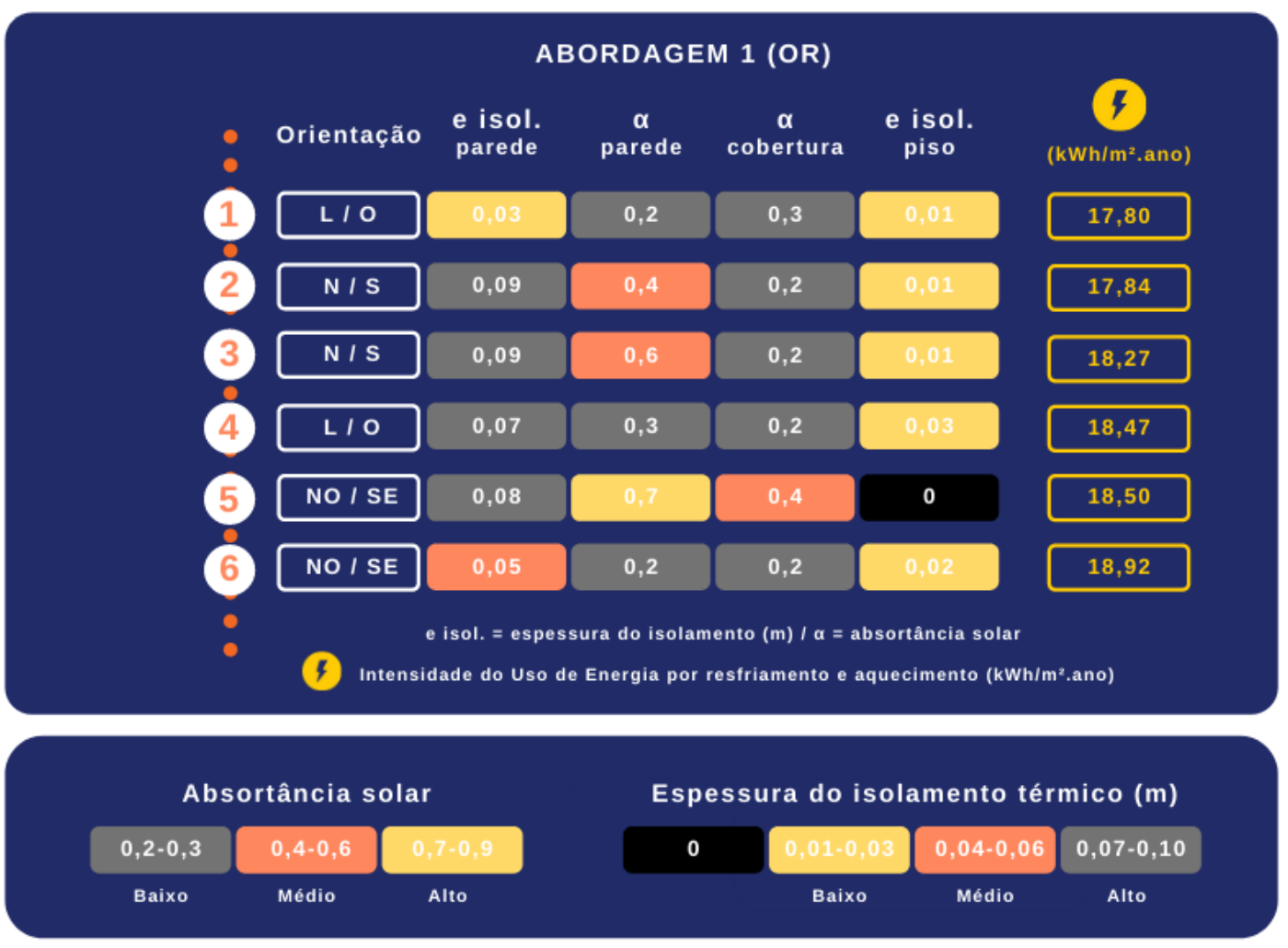

236 Maciel, T. dos S.; Leitzke, R. K.; Duarte, C. de M.; Schramm, F. K.; Cunha, E. G. da 
As soluções orientadas a NO/SE foram as que mais apresentaram diferenças em suas composições. Nessa abordagem o parâmetro definido pela espessura de isolamento do piso se manteve constante, com valores próximos ao mínimo. Além disso, foi constatado que o parâmetro com maior índice de variação é aquele que corresponde aos valores de absortância das paredes.

\section{Resultados da abordagem 2 (AND)}

A partir da plotagem dos resultados da abordagem 2 (Figura 10) é possível observar que já entre as primeiras gerações existe um princípio de convergência das soluções em direção ao ponto ótimo. Com o passar das gerações a concentração dos resultados na parte central se mantém, mas uma dispersão entre esses pontos pode ser observada após a execução de cinco gerações. Isso acontece pelo fato de o algoritmo conseguir identificar melhores soluções no eixo x (IUE resfriamento) e essas soluções naturalmente aumentarem um pouco do consumo por aquecimento, embora esses valores não sejam expressivos, próximos de 0,30 e 0,60 $\mathrm{kWh} / \mathrm{m}$.ano.

É possível observar ainda que após a execução de 7 gerações, os resultados ficam próximos dos valores já identificados entre as primeiras gerações, e, nesse caso, piores que aqueles observados na quinta. Busca-se nessa abordagem que o gargalo da análise aconteça dentro de um conjunto de soluções mais próximas possíveis do ponto ótimo, mas isso não acontece. Nesse caso, assim como na abordagem 1, é evidente que o algoritmo explora mais as gerações iniciais e não consegue afunilar e convergir esses resultados com o tempo, o que pode representar uma limitação dessas abordagens.

Apesar dos apontamentos, a abordagem AND cumpriu o papel pretendido pela análise. Foram alcançadas soluções com IUE resfriamento entre 15,06 e $28,38 \mathrm{kWh} / \mathrm{m}$.ano e IUE Aquecimento entre 0,24 e 0,45 $\mathrm{kWh} / \mathrm{m}$.ano, nas quais os valores mínimos já representam uma grande diferença se comparados ao consumo da solução base.

A melhor solução encontrada pela abordagem 2 também foi identificada após a execução de 5 gerações e consome $15,06 \mathrm{kWh} / \mathrm{m}$.ano de energia para resfriamento e $0,45 \mathrm{kWh} / \mathrm{m}$.ano para aquecimento. Esse resultado representa cerca de $33 \%$ e $73 \%$ de redução em relação a solução base. Com AND a funçãoobjetivo de IUE resfriamento alcançou resultados mais satisfatórios que a abordagem 1.

Das 16 soluções que fazem parte da Fronteira de Pareto, somente 4 passaram pelo critério da diferença máxima de $10 \%$ da melhor solução, os demais resultados apresentaram valores superiores a esse ou até mesmo a solução base. Dentro das melhores soluções, apesar da solução ótima ser voltada para NO/SE, foram identificados casos com faces para outras duas orientações, N/S e nordeste (NE) / sudoeste (SO), como mostra a Figura 11.

Com base nessas soluções, é possível observar que a única variável com característica semelhante para todas composições é o isolamento do piso. Na maior parte das soluções esse parâmetro aparece como nulo ou apenas com o limite inferior.

Com as maiores fachadas voltadas a NO/SE, a edificação apresenta dois tipos de composições e pouca diferença em relação ao seu consumo. Diferente da melhor solução, a solução 2 apresenta um elevado isolamento térmico do envelope, tanto nas paredes quanto na cobertura, que já é isolada desde o modelo inicial.

$\mathrm{Na}$ configuração N/S, o envelope vertical apresenta o mesmo nível de isolamento que o caso anterior, porém com coeficientes de absorção solar elevados. E, por fim, na NE/SO a composição apresenta valores médios, com exceção da cor das paredes, que faz com que a taxa de radiação solar absorvida seja menor.

Figura 10 - Resultados da abordagem 2
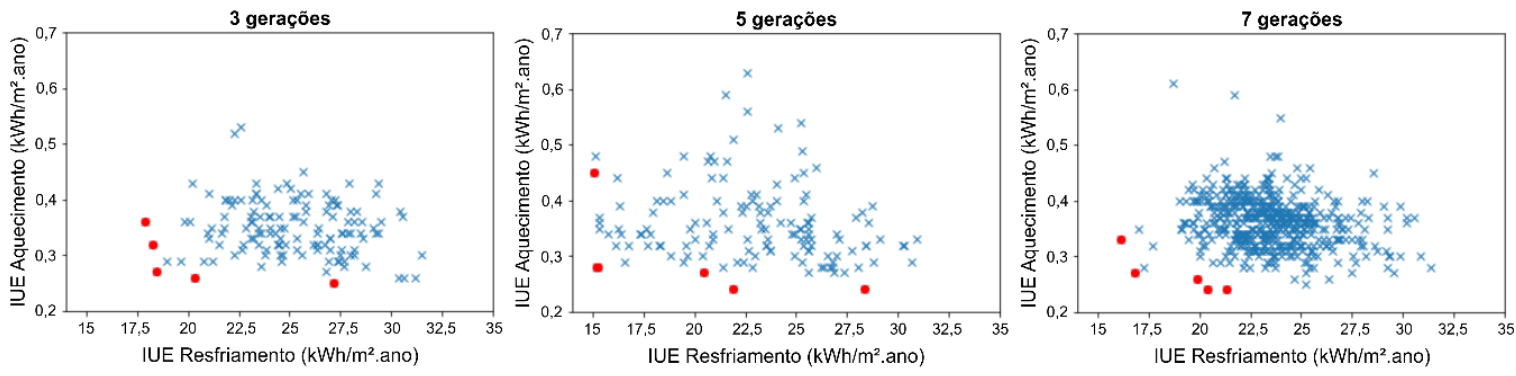

$x$ Todas as soluçōes - Fronteira de Pareto 
Figura 11 - Composição das melhores soluções encontradas pela abordagem AND
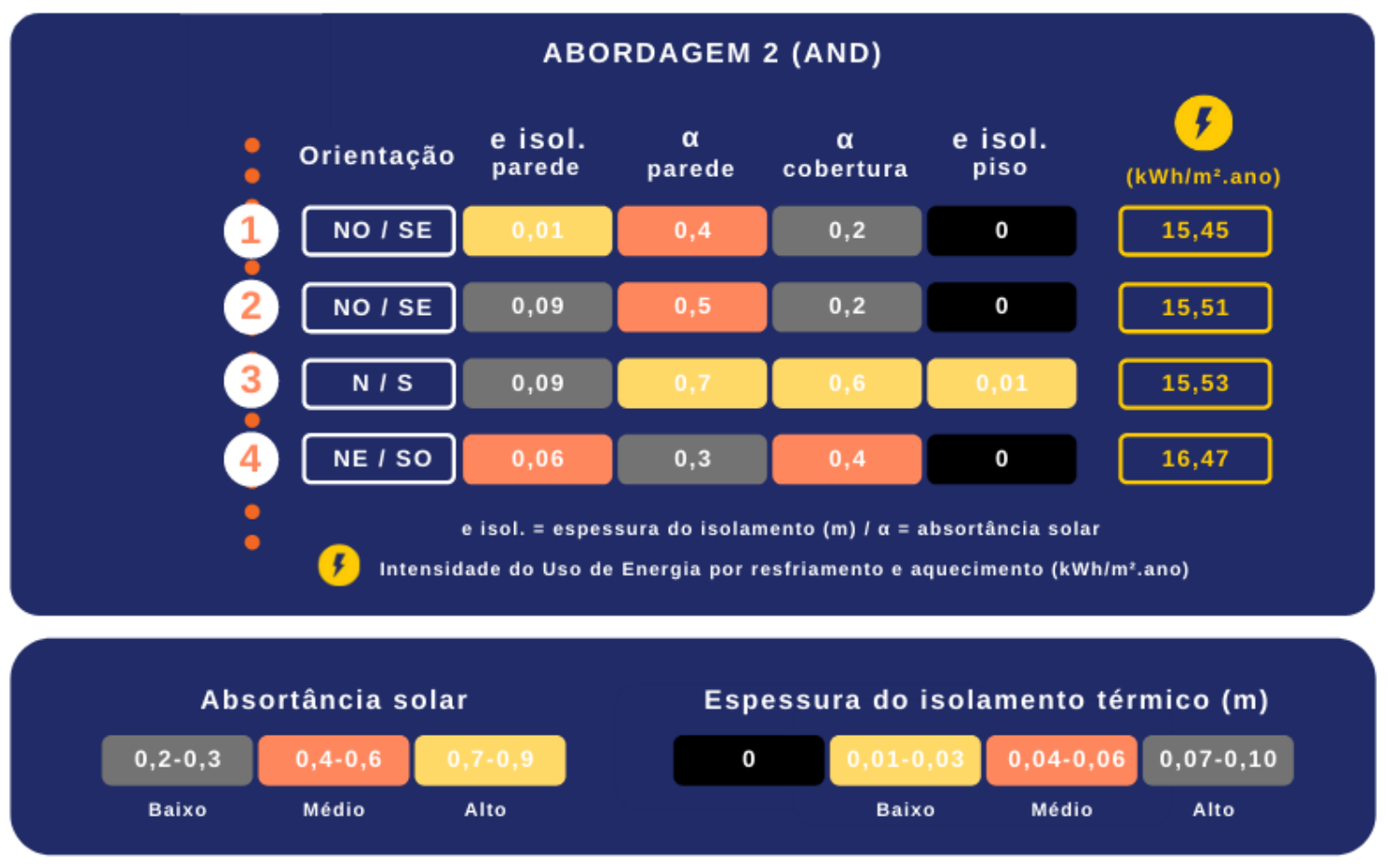

Essa disparidade entre as características de uma mesma solução demonstra aquilo que já foi citado anteriormente. A complexidade do desempenho de uma edificação varia em função da relação entre vários fatores, o que a faz ser caracterizada como um sistema complexo e ao mesmo tempo único, no qual inúmeras composições podem ser efetivas para resultados eficientes.

\section{Resultados da abordagem 3 (NSGA-II)}

Em um contexto diferente das anteriores, a abordagem 3 foi realizada em um cenário de maior estabilidade de execução e, seguindo a proposta do algoritmo, com um maior número de gerações. Na Figura 12a são apresentados os resultados alcançados pelo NSGA-II, em uma sequência de 30, 50 e 100 gerações.

Nesse caso, a redução para os dois objetivos foi consideravelmente superior às outras duas abordagens. De forma semelhante ao que já foi observado, a maior redução acontece no eixo de aquecimento, onde a melhor solução proporciona um consumo $92 \%$ menor que o caso base. O segundo objetivo, referente ao resfriamento, representou uma redução da intensidade do uso de energia elétrica de $50 \%$ do modelo inicial. Esses resultados configuram uma abordagem mais eficiente, representando uma redução cerca de $17 \%$ superior à abordagem 2 .

A Figura 12b apresenta a melhor solução encontrada pela abordagem 3 (S3), após a execução de 100 gerações. Essa solução consome $11,22 \mathrm{kWh} / \mathrm{m}$.ano por resfriamento e $0,14 \mathrm{kWh} / \mathrm{m}$.ano por aquecimento. Nessa composição a escola apresenta maiores fachadas voltadas à orientação $\mathrm{N} / \mathrm{S}$, cobertura isolada e paredes com isolamento e valores médios de absortância solar.

Com a utilização do NSGA-II, 23 soluções passaram a fazer parte da Fronteira de Pareto e entre elas apenas 4 foram selecionadas pelo critério de análise, sendo $11,36 \mathrm{kWh} / \mathrm{m}$.ano o consumo por climatização artificial total da melhor solução.

Como pode ser observado na Figura 13, as soluções de análise dividem-se entre as orientações N/S e L/O. Ao que tudo indica, a partir dessa abordagem, padrões entre as soluções já podem ser observados, e agora, além da ausência de isolamento no piso, o parâmetro de absortância da cobertura também se mantém semelhante para todas as composições. 
Figura 12 - Resultados da abordagem 3
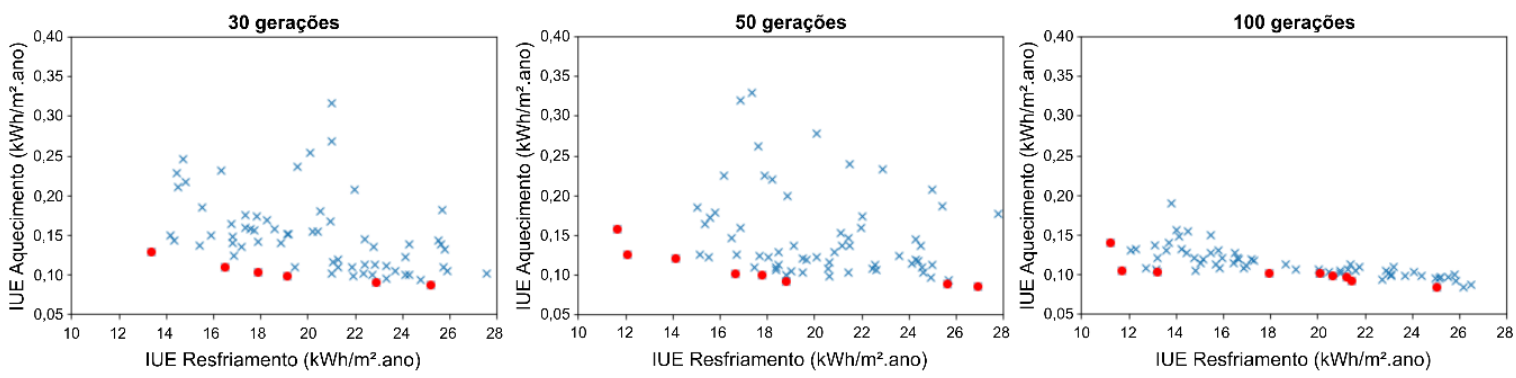

$x$ Todas as soluçōes - Fronteira de Pareto

(a)

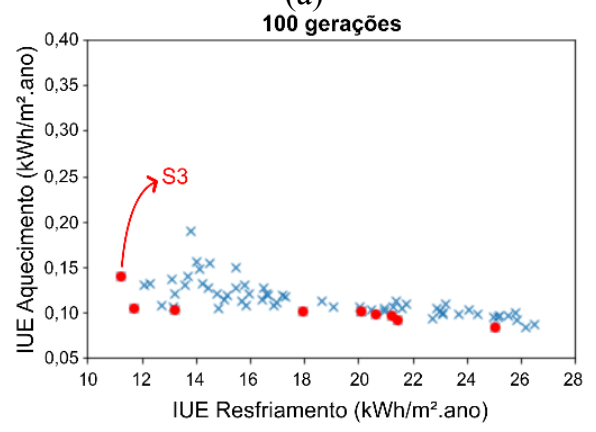

$\times$ Todas as soluções - Fronteira de Pareto

(b)

Figura 13 - Composição das melhores soluções encontradas pela abordagem NSGA-II
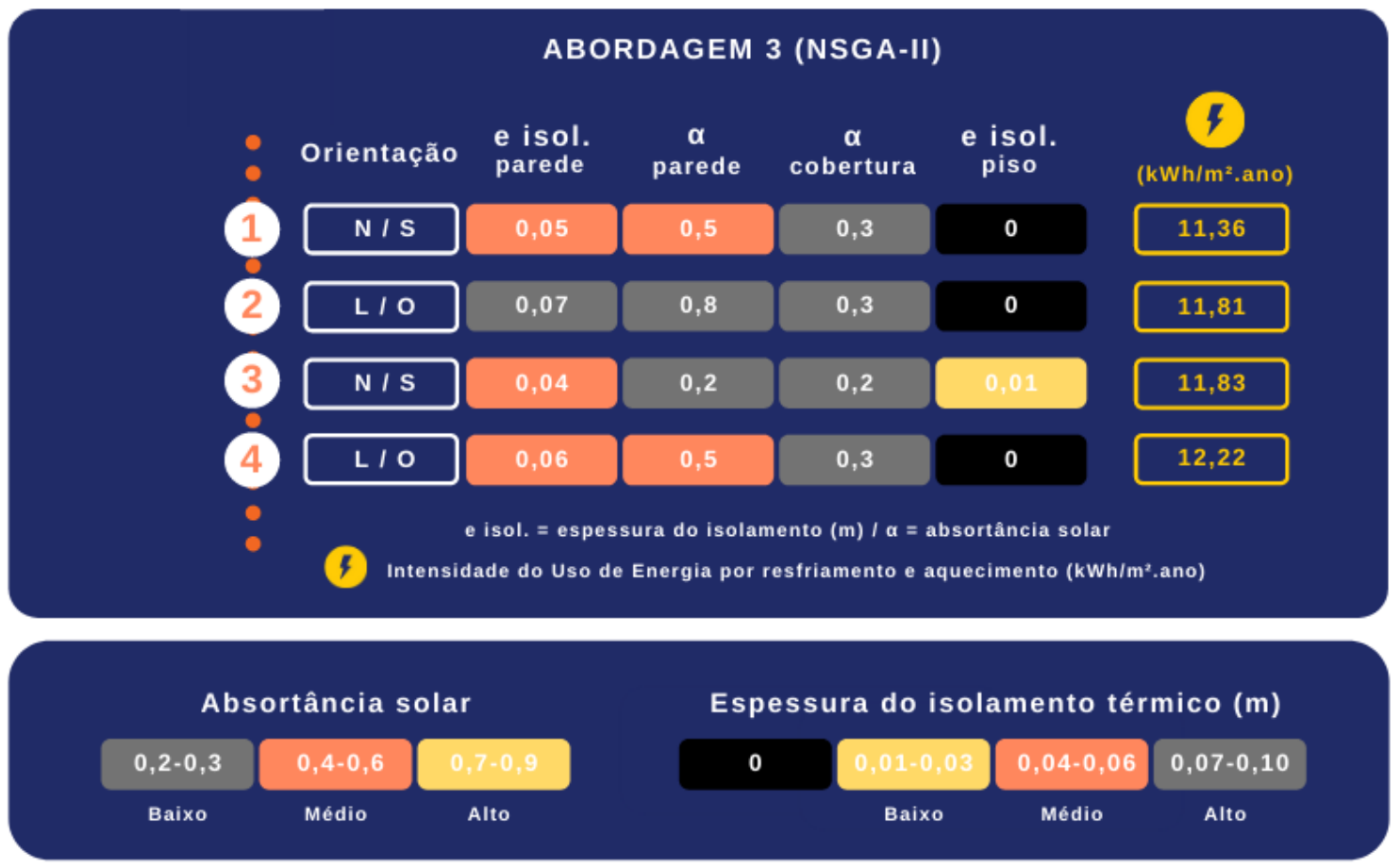

Ainda que existam duas composições para cada eixo de orientação, os limites encontrados pela análise para cada uma são diferentes, ou seja, a composição dessas edificações faz com que seus comportamentos também sejam diferentes, mesmo que voltadas para a mesma orientação. É provável que isso ocorra devido à presença de solários nessas fachadas, o que faz com que essa variável não seja tão influente sob o desempenho das demais. 
Ainda, observa-se que a orientação L/O é a que apresenta a solução com maior capacidade de isolamento e de forma inusitada, as soluções 1 e 4 possuem caracterização das variáveis muito semelhantes, e orientações distintas, demonstrando a interferência que a proteção solar exerce sobre a edificação.

\section{Resultados da abordagem 4 (SPEA2)}

O SPEA2 foi o algoritmo com melhor comportamento quando aplicado ao objeto de estudo. Além de ser a abordagem com o maior número de soluções identificadas através Fronteira de Pareto, obteve a composição da edificação com a menor IUE para resfriamento (Figura 14).

De forma semelhante ao que já foi observado, a melhor solução foi identificada após a execução de 100 gerações e a maior redução fica a cargo do eixo responsável pela IUE por aquecimento, 92\% menor que o caso base. O segundo objetivo, referente ao resfriamento, reduz cerca de $52 \%$ do modelo inicial. Esses resultados configuram uma abordagem mais eficiente, representando uma redução cerca de 19\% superior à abordagem 2 .

Através do critério de seleção, nessa abordagem também puderam ser observadas apenas duas composições, ambas com as maiores fachadas orientadas a N/S. Conforme apresentado na Figura 15, as soluções apresentam composições muito semelhantes, porém a melhor delas apresenta um baixo isolamento no envelope térmico vertical. Provavelmente isso ocorre devido ao excesso de calor interno, já que um elevado isolamento térmico em todo o envelope pode ser prejudicial ao desempenho da edificação, que não conseguirá dissipar esse calor para o exterior, aumentando a demanda pelo uso de climatização para resfriamento. Isso responde também a ausência de isolamento no piso para todas as soluções, onde o calor acumulado no interior da edificação deve ser dissipado para o solo.

Figura 14 - Melhor solução encontrada pela abordagem 4

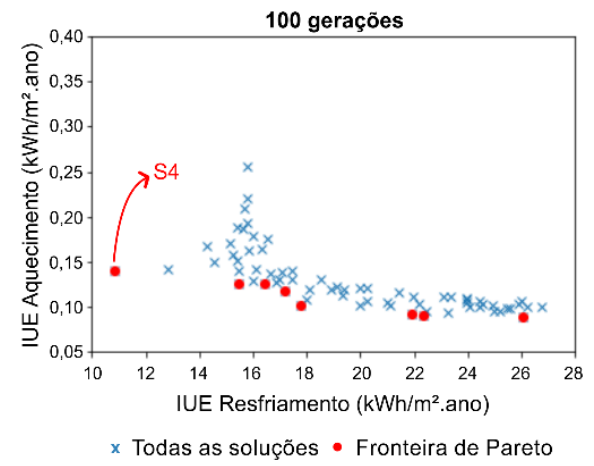

Figura 15 - Composição das melhores soluções encontradas pela abordagem SPEA2
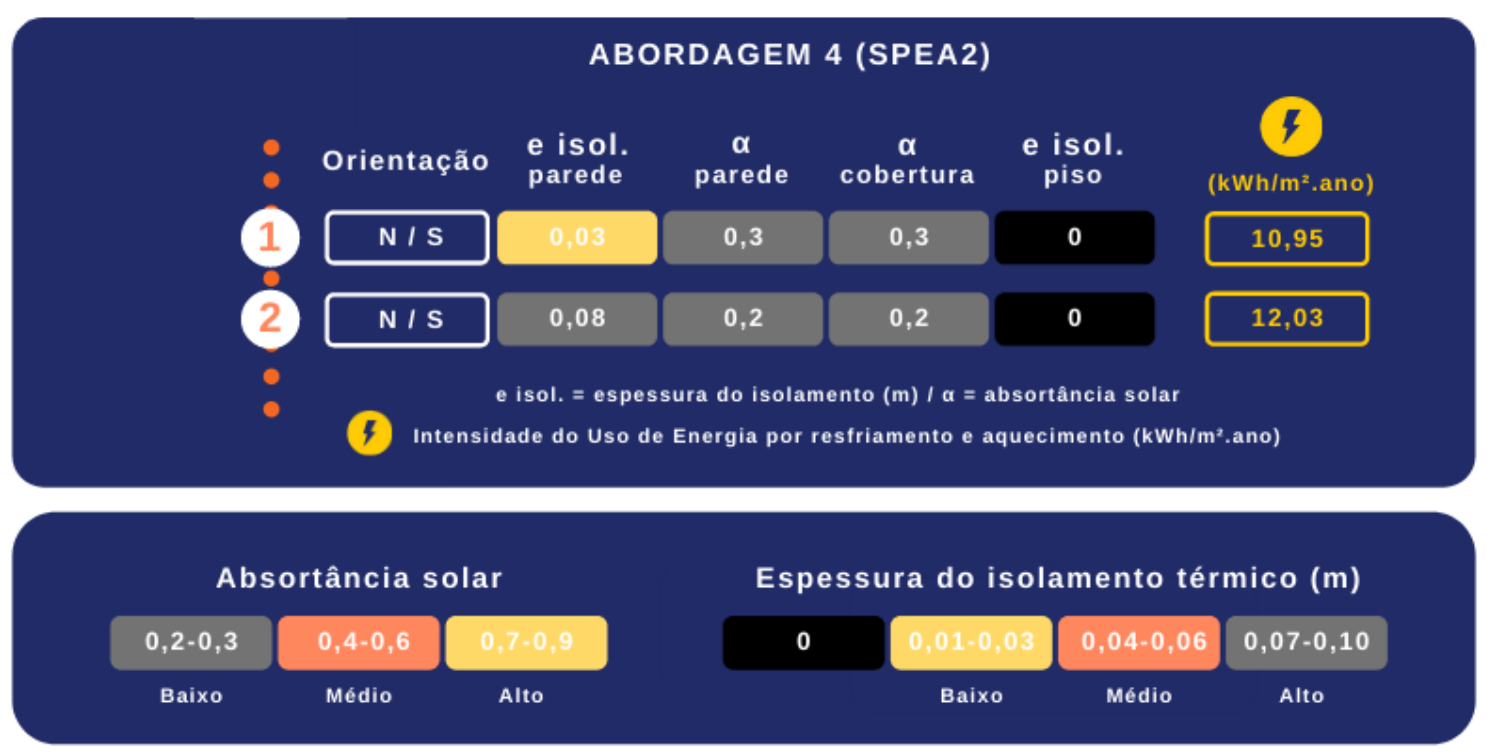

240 Maciel, T. dos S.; Leitzke, R. K.; Duarte, C. de M.; Schramm, F. K.; Cunha, E. G. da 


\section{Características das melhores soluções}

Todas as abordagens apresentaram diferenças significativas em relação ao consumo alcançado pela análise com aquele referente ao caso base. Apesar da dificuldade de identificação de padrões compositivos pelas análises anteriores, observa-se que as melhores soluções apresentam características de envelope muito semelhantes (Figura 16). Essas soluções foram definidas com paredes de baixo/médio isolamento, cobertura com elevado isolamento térmico, e piso com baixo/nulo isolamento.

A partir desses resultados observa-se que, nesse edifício, o parâmetro de orientação não foi um dos mais influentes para o desempenho da edificação. Isso ocorreu devido à presença de solários localizados na frente dos ambientes de permanência prolongada, ocupando as duas fachadas com maior abertura envidraçada. Esses elementos atuam na proteção solar de praticamente toda a extensão da edificação durante a maior parte do dia. As demais fachadas possuem janelas menores e ambientes secundários.

Nota-se também que o coeficiente de absortância solar da cobertura é o único que se mantém dentro dos mesmos limites para todas as soluções e, aparentemente, isso acontece devido ao elevado isolamento térmico que esse elemento apresenta desde o caso base. Dessa forma, não é necessário que o restante do envelope seja isolado, já que um excessivo isolamento também pode ser prejudicial ao desempenho da edificação. Nesse caso, onde a necessidade de resfriamento é maior, uma composição com menor isolamento pode auxiliar o processo de troca desse calor com o exterior.

Por esse motivo, apesar das semelhanças entre as melhores soluções das abordagens 1 (OR) e 4 (SPEA2), a camada de $1 \mathrm{~cm}$ de isolamento no piso presente na solução 1 contribui com o sobreaquecimento da edificação, pois não permite que o calor interno seja dissipado para o solo, aumentando o consumo referente ao eixo de IUE por resfriamento.

\section{Análise do desempenho e dos custos computacionais}

Quanto ao desempenho computacional dessas abordagens, o tempo médio de simulação do modelo base foi de aproximadamente 12 minutos e 26 segundos, considerando a complexidade do modelo e a quantidade de zonas térmicas. No total foram realizadas 27.324 simulações, 2.484 nas abordagens OR e AND e 24.840 com os algoritmos NSGA-II e SPEA2.

Figura 16 - Caracterização da melhor solução de cada uma das abordagens
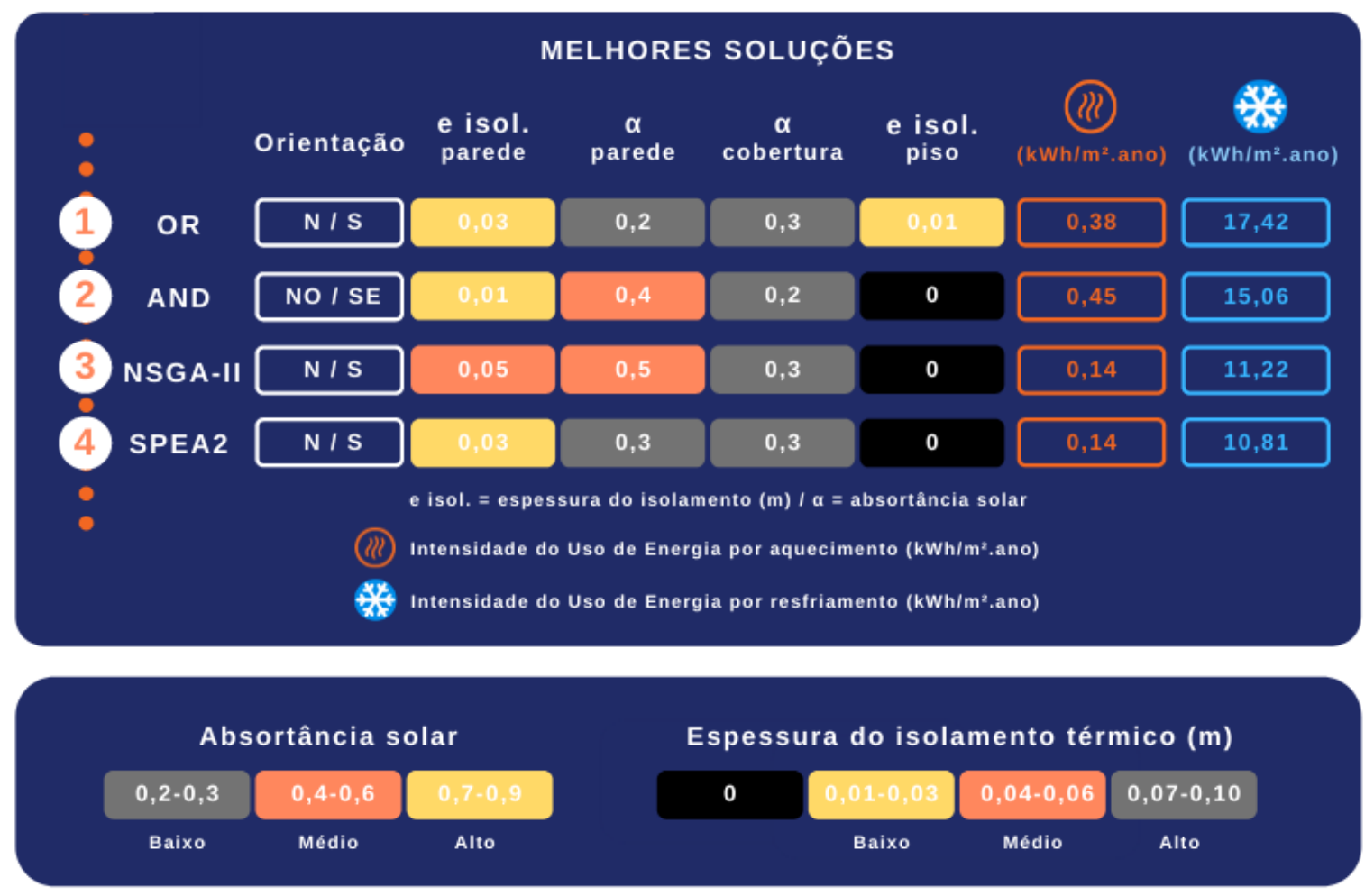
As abordagens 1 (OR) e 2 (AND) foram executadas em um contexto de 69 indivíduos em 3, 5 e 7 gerações. O tempo médio de execução para cada solução foi aproximadamente o mesmo, cerca de 1 minuto e 79 segundos e 1 minuto e 85 segundos, respectivamente. As soluções foram executadas paralelamente nos 8 núcleos de processamento disponíveis no computador, e nessas condições as abordagens custaram em tempo de execução aproximadamente 33 horas para OR e 34 horas para AND. Esses resultados enfatizam a importância de considerar o uso de paralelismo computacional para esse tipo de análise já que sem essa estratégia seriam necessários aproximadamente 27.324 minutos para execução das duas abordagens, o que representa algo em torno de 19 dias.

Em um cenário diferente das primeiras abordagens, para execução do NSGA-II e do SPEA2 foram considerados os mesmos 69 indivíduos, com uma condição de 30, 50 e 100 gerações, conforme proposta evolutiva dos algoritmos. Para finalização das análises foram necessárias cerca de 13 horas para cada uma das abordagens. Isso demonstra que à medida que a complexidade dos experimentos aumenta, torna-se necessária a investigação de um ambiente que apresente melhor capacidade de processamento e maior estabilidade de execução dos cenários, como é caso da plataforma BESOS. Além de possibilitar melhores resultados para ambas as funções-objetivo propostas por este estudo, a utilização desses algoritmos representou uma grande redução no custo computacional observado anteriormente. Isso acontece pela possibilidade de paralelização no âmbito de instrução, permitindo a execução das gerações em modo simultâneo, o que se torna mais barato no sentido computacional.

Um resumo das abordagens com seus respectivos resultados e custos computacionais são apresentados na Figura 17.

\section{Considerações finais}

Levando em conta os trabalhos identificados na revisão de literatura e a discussão sobre a execução das abordagens propostas pelo método e seus respectivos resultados, pode-se afirmar que a utilização de algoritmos evolutivos multiobjetivo contribui de forma relevante na identificação de soluções compositivas capazes de auxiliar na redução da intensidade do uso de energia elétrica de uma edificação.

Nesse caso, todas as abordagens reduziram a IUE da edificação para ambos os eixos, e no cenário das melhores soluções estas foram definidas com paredes de baixo e médio isolamento térmico, cobertura com elevado isolamento térmico e piso com baixo, ou nulo, isolamento. A variável definida pela orientação solar foi identificada como aquela de menor influência para essa edificação, considerando a presença de proteção solar nas fachadas com maior área envidraçada.

\section{Figura 17 - Desempenho das abordagens}

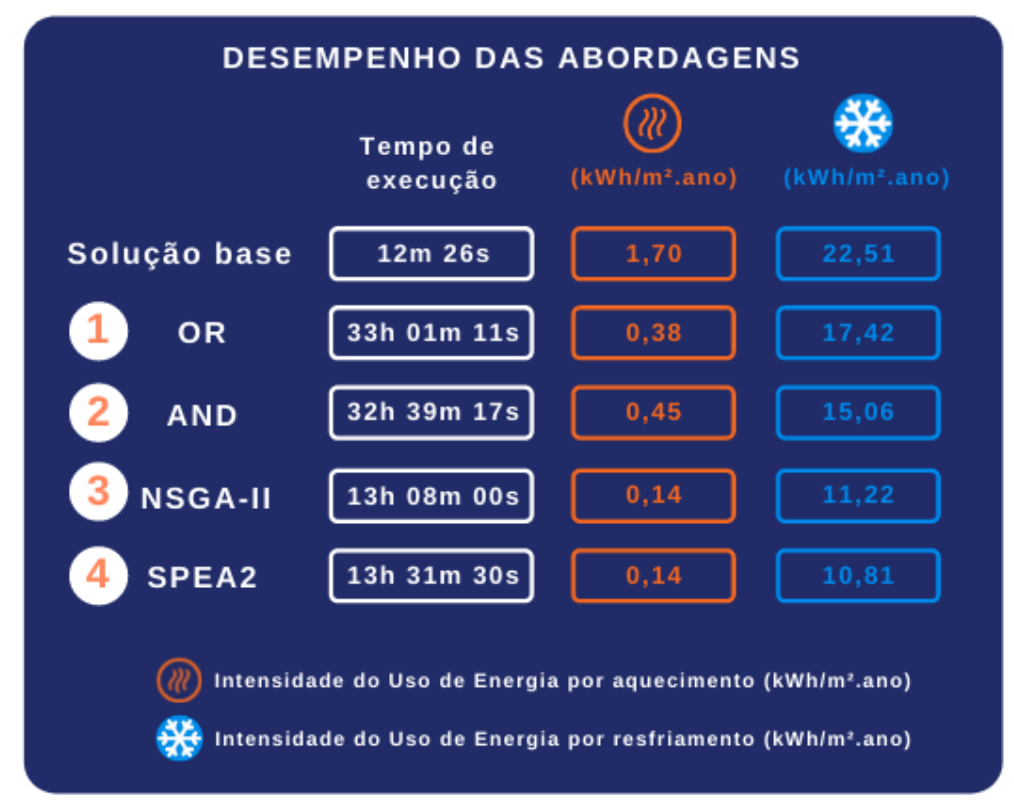

242 Maciel, T. dos S.; Leitzke, R. K.; Duarte, C. de M.; Schramm, F. K.; Cunha, E. G. da 
A abordagem 2 (SPEA2) foi a que apresentou melhor desempenho, tanto computacional quanto com relação aos resultados das funções objetivo. Além de um menor custo computacional, com uma execução de apenas 13 horas, essa abordagem alcançou a composição de edificação com a menor IUE, reduzindo cerca de $92 \%$ para resfriamento e $52 \%$ para aquecimento em relação ao consumo observado no caso base.

Considerando o baixo desempenho que tem sido observado nas edificações, pode ser interessante que esse tipo de otimização passe a integrar as etapas do processo de projeto. A combinação de procedimentos convencionais com abordagens inteligentes e tecnológicas, no sentido computacional, é capaz de auxiliar no processo de compreensão da influência que cada parâmetro exerce sobre o desempenho dos edifícios antes mesmo da sua construção.

A dificuldade de observação de padrões compositivos durantes as análises demonstram a complexidade de avaliação desse tipo de sistema, no qual podem ser observadas diversas soluções com características de composições distintas e IUE equivalentes, ou vice-versa, reafirmando a autenticidade de uma edificação. Por outro lado, cabe ressaltar que a escolha entre as abordagens é uma tarefa fundamental para um bom desempenho dessas análises e os resultados apresentados neste trabalho são específicos ao objeto de estudo definido para essa aplicação.

\section{Referências}

AMERICAN SOCIETY OF HEATING, REFRIGERATION AND AIR CONDITIONING ENGINEERS. Standard 55: thermal environmental conditions for human occupancy. Atlanta, 2013.

ASADI, E. et al. A multi-objective optimization model for building retrofit strategies using TRNSYS simulations, GenOpt and MATLAB. Building and Environment, v. 56, p. 370-378, 2012.

ASSOCIAÇÃO BRASILEIRA DE NORMAS TÉCNICAS. NBR 15220-2: desempenho térmico de edificações: parte 2: métodos de cálculos da transmitância térmica, da capacidade térmica, do atraso térmico e do fator solar de elementos e componentes de edificações. Rio de Janeiro, 2005a.

ASSOCIAÇÃO BRASILEIRA DE NORMAS TÉCNICAS. NBR 15220-3: desempenho térmico de edificações: parte 3: zoneamento bioclimático brasileiro e diretrizes construtivas para habitações de unifamiliares de interesse social. Rio de Janeiro, 2005b.

ATTIA, S. Computational optimization for Zero Energy Building design: interviews with 28 international experts. International Energy Agency (IEA) Task 40: Towards Net Zero Energy Buildings Subtask B. Louvain la Neuve: Université Catholique de Louvain, 2012.

BLUM, D. et al. Practical factors of envelope model setup and their effects on the perfoRmance of model predictive control for building heating, ventilating, and air conditioning systems. Applied Energy, v. 236, p. 410-425, 2019.

BRASIL. Ministério da Educação. Fundo Nacional para o Desenvolvimento da Educação. Resolução no 6 , 24 de abril de 2007. Brasília, 2007. Disponível em: https://www.fnde.gov.br/index.php/acesso-ainformacao/institucional/legislacao/item/3130-resolu\%C3\%A7\%C3\%A3o-cd-fnde-n $\% \mathrm{C} 2 \% \mathrm{BA}-6$-de-24-deabril-de-2007. Acesso em: 23 dez. 2020.

BRASIL. Ministério da Educação. Fundo Nacional para o Desenvolvimento da Educação. Projeto Proinfância Tipo 2. Fundo Nacional de Desenvolvimento da Educação - FNDE. Brasília, 2017. Disponível em: http://www.fnde.gov.br/index.php/programas/proinfancia/eixos-de atuacao/projetos-arquitetonicos-paraconstrucao/item/6413-proinfancia-tipo-2. Acesso em: 20 ago. 2020.

BRE, F.; FACHINOTTI, V. D. A computational multi-objective optimization method to improve energy efficiency and thermal comfort in dwellings. Energy and Buildings, v. 154, 283-294, 2017.

CABEZA, L. F. et al. Life cycle assessment (LCA) and life cycle energy analysis (LCEA) of buildings and the building sector: a review. Renewable and Sustainable Energy Reviews, v. 29, p. 394-416, 2014.

CENTER FOR THE BUILT ENVIRONMENT. About mixed-mode. Disponível em: https://cbe.berkeley.edu/mixedmode/index.html. Acesso em: 07 out. 2020.

CHARTERED INSTITUTION OF BUILDING SERVICES ENGINEERS. AM13 Mixed mode ventilation. Grã-Bretanha, 2000.

COAKLEY, D.; RAFTERY, P.; KEANE, M. A review of methods to match building energy simulation models to measured data. Renewable and Sustainable Energy reviews, v. 37, p. 123-141, 2014. 
COELLO, C. A. C. et al. Evolutionary algorithms for solving multi-objective problems. Springer, v. 5. 2007.

DAHLAN, N.; ARIS, A. Optimizing energy baseline for medium size office using hybrid EnergyPlusEvolutionary Programming (EP). Journal of Telecommunication, Electronic and Computer Engineering, v. 10, n. 1-4, p. 59-65, 2018.

DANIEL, W. W.; CROSS, C. L. Biostatistics: a foundation for analysis in the health sciences. $11^{\text {th }}$. ed. New York: John Wiley \& Sons, 2018.

DEB, K. et al. A fast and elitist multiobjective genetic algorithm: NSGA-II. IEEE transactions on evolutionary computation, v. 6, n. 2, p. 182-197, 2002.

DIDONÉ, E. L.; PEREIRA, F. O. R. Simulação computacional integrada para a consideração da luz natural na avaliação do desempenho energético de edificações. Ambiente Construído, Porto Alegre, v. 10, n. 4, p. 139-154, out./dez. 2010.

DUBOIS, D.; DUBOIS, E. F. A formula to estimate the approximate surface area if height and weight be known. Archives Internal Medicine, v. 17, n. 862, 1916.

DUSSAULT, J.-M.; GOSSELIN, L. Office buildings with electrochromic windows: a sen- sitivity analysis of design parameters on energy performance, and thermal and visual comfort. Energy and Buildings, v. 153, p. 50-62, 2017.

ECHENAGUCIA, T. M. et al. The early design stage of a building envelope: Multi-objective search through heating, cooling and lighting energy performance analysis. Applied Energy, v. 154, p. 577-591, 2015.

ELETROBRAS. Programa Nacional de Conservação de Energia Elétrica. Estimativa de consumo médio mensal de equipamentos. Rio de Janeiro, 2016. Disponível em:

http://www.procelinfo.com.br/main.asp?View=\%7BE6BC2A5F-E787-48AF-B485-439862B17000\%7D. Acesso em: 20 ago. 2020.

EMPRESA DE PESQUISA ENERGÉTICA. Balanço energético nacional: relatório síntese, ano base 2019. Rio de Janeiro: Ministério de Minas e Energia, 2020.

ENERGY INCITIES. Building and Energy Systems Optimization and Surrogate-modelling - BESOS. Disponível em: https:/gitlab.com/energyincities/besos/. Acesso em: 7 out. 2020.

EVINS, R. A review of computational optimisation methods applied to sustainable building design. Renewable and Sustainable Energy Reviews, v. 22, p. 230-245, 2013.

FOGEL, L. J. Autonomous automata. Industrial Research, v. 4, p. 14-19, 1962.

FONSECA, L. P. G. et al. Otimização multiobjetivo das dimensões dos ambientes de uma residência unifamiliar baseada em simulação energética e estrutural. Ambiente Construído, Porto Alegre, v. 17, n. 1, p. 267-288, 2017.

GAN, V. J. et al. Simulation-based evolutionary optimization for energy-efficient layout plan design of high-rise residential buildings. Journal of Cleaner Production, v. 231, p. 1375-1388, 2019.

HU, J.; KARAVA, P. Model predictive control strategies for buildings with mixed-mode cooling. Building and Environment, v. 71, p. 233-244, 2014.

HUANG, Z. et al. Back-analysis and parameter identification for deep excavation based on Pareto multiobjective optimization. Journal of Aerospace Engineering, v. 28, n. 6, 2015.

INSTITUTO NACIONAL DE METROLOGIA, QUALIDADE E TECNOLOGIA. Regulamento Técnico da Qualidade para o Nível de Eficiência Energética Edificações Comercias, de Serviços e Públicas. Portaria n. ${ }^{\circ}$ 372, de 17 de setembro de 2010. Disponível em:

http://pbeedifica.com.br/sites/default/files/projetos/etiquetagem/comercial/downloads/Port3722010_RTQ_Def_Edificacoes-C_rev01.pdf. Acesso em: 7 out. 2020.

KHOROSHILTSEVA, M.; SLANZI, D.; POLI, I. A Pareto-based multi-objective optimi- zation algorithm to design energy-efficient shading devices. Applied Energy, v. 184, p. 1400-1410, 2016.

KIRIMTAT, A. et al. Multi-objective energy and daylight optimization of amorphous shading devices in buildings. Solar Energy, v.185, p. 100-111, 2019.

244 Maciel, T. dos S.; Leitzke, R. K.; Duarte, C. de M.; Schramm, F. K.; Cunha, E. G. da 
KOWALTOWSKI, D. C. Arquitetura escolar: o projeto do ambiente de ensino. São Paulo: Oficina de textos, 2011.

LEE, S. H. et al. Accelerating the energy retrofit of commercial buildings using a database of energy efficiency performance. Energy, v. 90, p. 738-747, 2015.

LEITZKE, R. K. et al. Optimization of the traditional method for creating a weather simulation file: the Pelotas.epw case. Journal of Civil Engineering and Architecture, v. 12, p. 741-756, 2018.

LI, X.; MALKAWI, A. Multi-objective optimization for thermal mass model predictive control in small and medium size commercial buildings under summer weather conditions. Energy, v. 112, p. 1194-1206, 2016.

LINCZUK, V. C. C.; BASTOS, L. E. G. Otimização multiobjetivo orientada ao desempenho térmico para o projeto de edificações de baixo consumo de energia na Região Sul do Brasil. Ambiente Construído, Porto Alegre, v. 20, n. 4, p. 509-529, out./dez. 2020.

MILlMAN, K. J.; AIVAZIS, M. Python for scientists and engineers. Computing in Science \& Engineering, v. 13, n. 2, p. 9-12, 2011.

NGATCHOU, P.; ZAREI, A.; EL-SHARKAWI, A. Pareto multi objective optimization. In: INTERNATIONAL CONFERENCE ON, INTELLIGENT SYSTEMS APPLICATION TO POWER SYSTEMS, 3., Arlington, 2005. Proceedings [...] Arlington, 2005.

NGUYEN, A.T.; REITER, S.; RIGO, P. A review on simulation-based optimization methods applied to building performance analysis. Applied Energy, v. 113, p. 1043-1058, 2014.

NIMLYAT, P.; DASSAH, E.; ALLU, E. Computer simulations in buildings: implications for building energy performance. Computer, v. 4, n. 3, 2014.

OLIVEIRA, L. S. Avaliação dos limites das propriedades térmicas dos fechamentos opacos da NBR 15220-3, para habitações de interesse social, da Zona Bioclimática 2. Pelotas, 2012. 168 f. Dissertação (Mestrado em Arquitetura e Urbanismo) - Programa de Pós-Graduação em Arquitetura e Urbanismo, Universidade Federal de Pelotas, Pelotas, 2012.

PAN, L. et al. Multi-objective optimization for building performance design considering thermal comfort and energy consumption. In: CHINESE CONTROL CONFERENCE, Chengdu, 2016. Proceedings [...] Chengdu, 2016.

PARETO, V. Cours D'économie Politique. Lausanne: F. Rouge, 1896.

PHILIP, S.; TRAN, T.; TANJUATCO, L. Eppy: scripting language for E+. Disponível em: https://github.com/santoshphilip/eppy. Acesso em: 7 out. 2020.

SAMPAIO, P. R. Teoria, métodos e aplicações de otimização multiobjetivo. São Paulo, 2011.95 f. Dissertação (Mestrado em Ciência da Computação) - Instituto de Matemática e Estatística, Universidade de São Paulo, São Paulo, 2011.

SOARES, M. M. Avaliação dos Parâmetros de Desempenho Térmico da NBR 15575/2013: habitações de interesse social na zona bioclimática 2. Pelotas, 2014. 159 f. Dissertação (Mestrado em Arquitetura e Urbanismo) - Programa de Pós-Graduação em Arquitetura e Urbanismo, Universidade Federal de Pelotas, Pelotas, 2014.

SOUSA, J. Energy simulation software for buildings: review and comparison. In: INTERNATIONAL WORKSHOP ON INFORMATION TECHNOLOGY FOR ENERGY APPLICATIONS, Lisboa, 2012. Proceedings [...] Lisboa: Ordem dos Engenheiros, 2012.

TONG, Z. et al. A case study of air quality above an urban roof top vegetable farm. Environmental Pollution, v. 208, p. 256-260, 2016 b.

TONG, Z. et al. Quantifying the impact of traffic-related air pollution on the indoor air quality of a naturally ventilated building. Environment International, v. 89, p. 138-146, 2016a.

WU, M. H.; NG, T. S.; SKITMORE, M. R. Sustainable building envelope design by considering energy cost and occupant satisfaction. Energy for Sustainable Development, v. 31, p. 118-129, 2016.

YAN, C. et al. A seasonal cold storage system based on separate type heat pipe for sustainable building cooling. Renewable Energy, v. 85, p. 880-889, 2016. 
YIGIT, S.; OZORHON, B. A simulation-based optimization method for designing energy efficient buildings. Energy and Buildings, v. 178, p. 216-227, 2018.

YU, W. et al. Application of multi-objective genetic algorithm to optimize energy efficiency and thermal comfort in building design. Energy and Buildings, v. 88, p. 135-143, 2015.

ZALUSKI, P. R. S.; DANTAS, M. J. P. Application of simulation softwares in engineering education: a report of successful international experiences in modeling and system simulation courses. Brazilian Applied Science Review, v. 2, p. 170-181, 2018.

ZEMERO, B. R. Metodologia para o projeto preliminar de edifícios utilizando otimização multiobjetivo baseada na simulação de desempenho. Belém, 2019. $113 \mathrm{f}$. Tese (Doutorado em Engenharia Elétrica) - Programa de Pós Graduação em Engenharia Elétrica, Universidade Federal do Pará, Belém, 2019.

ZHAI, Y. et al. A multi-objective optimization methodology for window design considering energy consumption, thermal environment and visual performance. Renewable Energy, v. 134, p. 1190-1199, 2019.

ZHANG, Y.; KOROLIJA, I. Performing complex parametric simulations with jEPlus. In:

INTERNATIONAL CONFERENCE ON SUSTAINABLE ENERGY TECHNOLOGIES, 9., Shangai, 2010. Proceedings [...] Shangai, 2010.

ZITZLER, E. et al. SPEA2: improving the strength Pareto evolutionary algorithm. TIK-report, v. 103, 2001.

\section{Agradecimentos}

O presente trabalho foi realizado com apoio da Coordenação de Aperfeiçoamento de Pessoal de Nível Superior - Brasil (CAPES) - Código de Financiamento 001.

\section{Thalita dos Santos Maciel}

Programa de Pós-Graduação em Arquitetura e Urbanismo | Universidade Federal de Pelotas | Rua Benjamin Constant, 1359, Centro | Pelotas - RS - Brasil | CEP 96010-020 | Tel.: (53) 3284-5511 | E-mail: thalita-maciel@hotmail.com

Rodrigo Karini Leitzke

Programa de Pós-Graduação em Arquitetura e Urbanismo | Universidade Federal de Pelotas | E-mail: rodrigokarinileitzke@gmail.com

\section{Carolina de Mesquita Duarte}

Programa de Pós-Graduação em Arquitetura e Urbanismo | Universidade Federal de Pelotas | E-mail:

carolinademesquitaduarte@hotmail.com

Fábio Kellermann Schramm

Programa de Pós-Graduação em Arquitetura e Urbanismo | Universidade Federal de Pelotas | Rua Benjamin Constant, 1359, sala 123, Centro | Pelotas - RS - Brasil | CEP 96010-020 | Tel.: (53) 3284-5510 | E-mail: fabioks@ufpel.edu.br

\section{Eduardo Grala da Cunha}

Programa de Pós-Graduação em Arquitetura e Urbanismo | Universidade Federal de Pelotas | Rua Benjamin Constant, 1359, Centro | Pelotas - RS - Brasil | CEP 96010-020 | Tel.: (53) 3284-5511 | E-mail: eduardogralacunha@yahoo.com.br

\section{Ambiente Construído}

Revista da Associação Nacional de Tecnologia do Ambiente Construído

Av. Osvaldo Aranha, $99-3^{\circ}$ andar, Centro

Porto Alegre - RS - Brasil CEP $90035-190$

Telefone: +55 (51) 3308-4084

www.seer.ufrgs.br/ambienteconstruido www.scielo.br/ac

E-mail: ambienteconstruido@ufrgs.br 